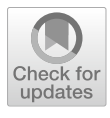

Cite as

Nano-Micro Lett. (2021) $13: 18$

Received: 16 June 2020

Accepted: 6 September 2020

Published online: 2 November 2020

(C) The Author(s) 2020

\section{An Overview on SARS-CoV-2 (COVID-19) and Other Human Coronaviruses and Their Detection Capability via Amplification Assay, Chemical Sensing, Biosensing, Immunosensing, and Clinical Assays}

\author{
Yasin Orooji ${ }^{1,2}$, Hessamaddin Sohrabi ${ }^{3}$, Nima Hemmat ${ }^{4}$, Fatemeh Oroojalian ${ }^{5}$, \\ Behzad Baradaran $^{4}$, Ahad Mokhtarzadeh ${ }^{凶}$, Mohamad Mohaghegh ${ }^{6}$, \\ Hassan Karimi-Maleh ${ }^{7,8,9} \bowtie$
}

\title{
HIGHLIGHTS
}

- Various amplification assays and sensing can be applied for the detection of SARS-CoV-2.

- The outputs of biosensors should be presented quantitatively to obtain more accurate and more accessible results.

- Developing smaller size platforms is one approach toward applying such phone apps, as well as utilizing LFA, biosensors, and nanobiosensors detection techniques.

\begin{abstract}
A novel coronavirus of zoonotic origin (SARSCoV-2) has recently been recognized in patients with acute respiratory disease. COVID-19 causative agent is structurally and genetically similar to SARS and bat SARS-like coronaviruses. The drastic increase in the number of coronavirus and its genome sequence have given us an unprecedented opportunity to perform bioinformatics and genomics analysis on this class of viruses. Clinical tests like PCR and ELISA for rapid detection of this virus are urgently needed for early identification of infected patients.

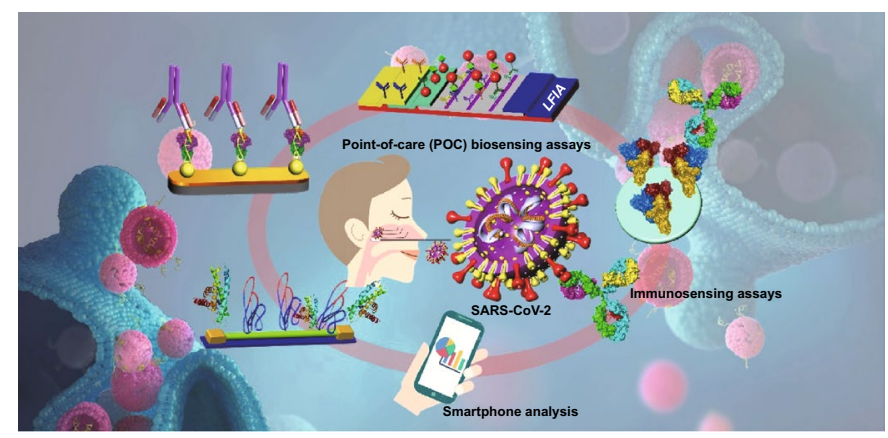
However, these techniques are expensive and not readily available for point-of-care (POC) applications. Currently, lack of any rapid, available, and reliable POC detection method gives rise to the progression of COVID-19 as a horrible global problem. To solve the negative features of clinical investigation, we provide a brief introduction of the general features of coronaviruses and describe various amplification assays, sensing, biosensing, immunosensing, and aptasensing for the determination of various groups of coronaviruses applied as a template for the detection of SARS-CoV-2. All sensing and biosensing techniques developed for the determination of various classes of coronaviruses are useful to recognize the newly immerged coronavirus, i.e., SARS-CoV-2. Also, the introduction of sensing and biosensing methods sheds light on the way of designing a proper screening system
\end{abstract}

Yasin Orooji and Hessamaddin Sohrabi have contributed equally to this work.

$\bowtie$ Yasin Orooji, yasin@njfu.edu.cn; Ahad Mokhtarzadeh, mokhtarzadehah@tbzmed.ac.ir; Hassan Karimi-Maleh, hassan@uestc.edu.cn

1 College of Materials Science and Engineering, Nanjing Forestry University, Nanjing 210037, People's Republic of China 
to detect the virus at the early stage of infection to tranquilize the speed and vastity of spreading. Among other approaches investigated among molecular approaches and PCR or recognition of viral diseases, LAMP-based methods and LFAs are of great importance for their numerous benefits, which can be helpful to design a universal platform for detection of future emerging pathogenic viruses.

KEYWORDS ELISA; qRT-PCR; Sensing assay; Apta assay; Amplification assay

\section{Introduction}

Coronaviruses are known due to their potency to infect human respiratory tracts causing common colds to severe illnesses such as pneumonia. The pathogenesis and epidemiology of these viruses were underestimated for a long time because of the lack of serious threat for human health until the end of 2002 when a novel, unknown severe acute respiratory syndrome (SARS) initiated to involve human, spread all around the world, and cause a high mortality rate. Given the genomic similarity, the SARS coronavirus (SARS-CoV) was introduced to be the causative infectious agent of this disease with more than 8000 cases (lethality rate of 774) [1]. While the mortality rate of this infection and its related disease was not comparable with previous viral pandemics, most of the public concerns about this infection were high global economic costs (\$30-100 billion) [2]. Depending on the viral load and the host immune profile, SARS-CoV can involve lower respiratory tracts in fatal pneumonia with the following symptoms: fatigue, headache, muscle pain, loss of appetite, lymphopenia, and rarely diarrhea. Despite many efforts to repress SARS outbreak, the Coronaviridae family puts its second pathogenic member forward a decade later, i.e., Middle East Respiratory Syndrome Coronavirus (MERS-CoV) [3].

For the first time, MERS-CoV has been detected in a patient who died from acute respiratory distress syndrome (ARDS) and renal failure in Saudi Arabia during the summer of 2012 [4]. Further studies demonstrated that this new virus could infect camels and bats, as well as humans [5]. The symptoms of MERS-CoV infection were the same as those of SARS-CoV due to its ability to involve lower respiratory tracts; however, the fusion within the host cells in MERS-CoV was mediated by dipeptidyl peptidase-4 (DPP4) receptor differing from angiotensin I, converting enzyme 2 (ACE2) receptors used by SARS-CoV through its entry into the host cells. By 2017, more than 2000 cases of MERS were reported with a mortality rate of approximately $30 \%$. The outbreak of MERS-COV began in Saudi Arabia, but due to air travel, the virus was able to reach other countries in the Middle East, including Jordan, Qatar, Egypt, Kuwait, and the United Arab Emirates, as well as countries outside the region such as Austria, South Korea, the USA, and the UK [6].

As a public health emergency of international concern, the Coronaviridae family has been reinforced and emerged with another lower respiratory tract infectious agent, i.e., SARS-CoV-2 and its related disease, Coronavirus Disease 2019 (COVID-19) [7]. The clinical manifestations of this infection were approximately similar to those of SARS, like pneumonia and cough.

In December 2019, the epicenter of the COVID-19 outbreak was found to be located in Wuhan, China. But, unfortunately, the number of infected countries has increased significantly since the declaration of COVID-19 as a public health emergency of international concern. This virus has spread to more than 130 countries, with over $23.057 \mathrm{M}$ confirmed cases and over $801 \mathrm{~K}$ confirmed deaths worldwide as of August 23, 2020 (Fig. 1) [8].

However, the mortality rate of this coronavirus infection seems to be more severe and higher than that of other members. The COVID-19 outbreak is still ongoing and has

\footnotetext{
2 Jiangsu Co-Innovation Center for Efficient Processing and Utilization of Forest Resources, Nanjing Forestry University, Nanjing 210037, People's Republic of China

3 Department of Analytical Chemistry, Faculty of Chemistry, University of Tabriz, Tabriz 51666-16471, Iran

4 Immunology Research Center, Tabriz University of Medical Sciences, Tabriz, Iran

5 Department of Advanced Sciences and Technologies in Medicine, School of Medicine, North Khorasan University of Medical Sciences, Bojnurd, Iran

6 Department of Nanobiotechnology, School of Biological Sciences, Tarbiat Modares University, Tehran, Iran

7 Department of Chemical Engineering, Laboratory of Nanotechnology, Quchan University of Technology, Quchan, Islamic Republic of Iran

8 School of Resources and Environment, University of Electronic Science and Technology of China, Xiyuan Ave, Chengdu 611731, People's Republic of China

9 Department of Chemical Sciences, University of Johannesburg, Doornfontein Campus, PO Box 17011, Johannesburg 2028, South Africa
} 


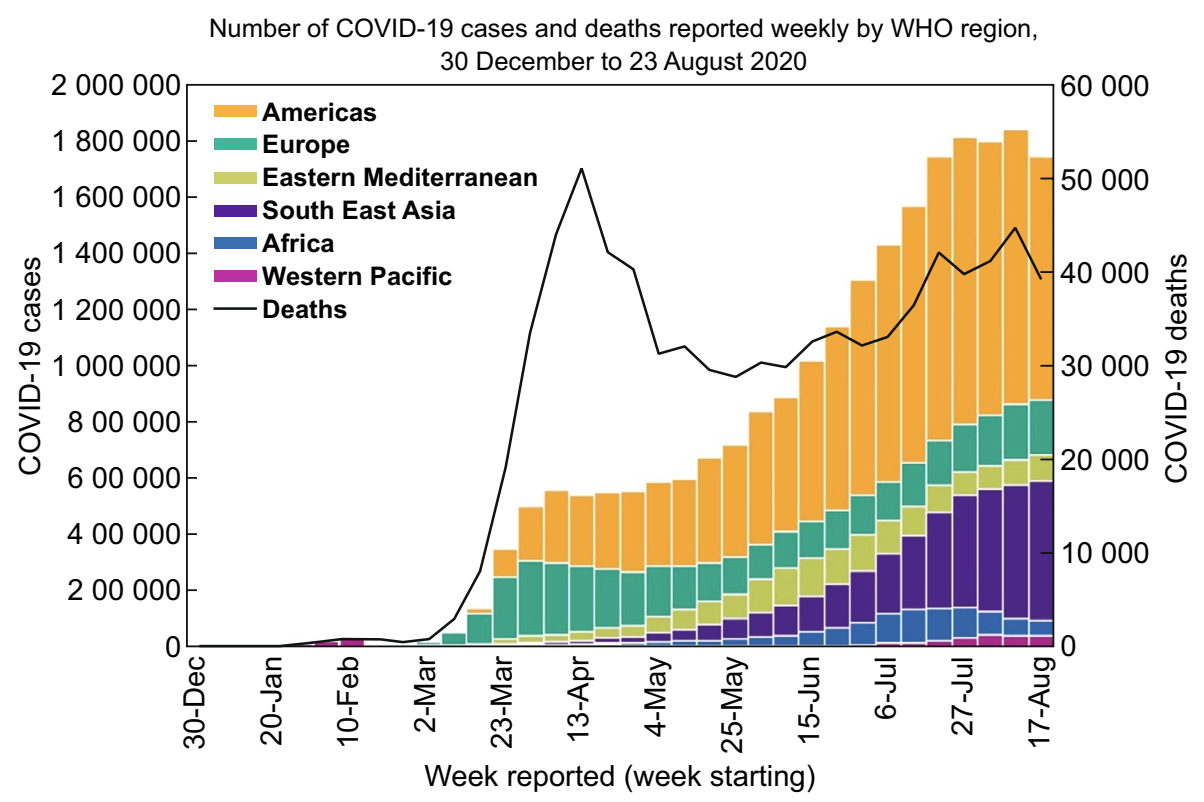

Fig. 1 Epidemic chart of confirmed COVID-19 up to August 23, 2020. Used with permission from Ref. [8]. Copyright 2020 World Health Organization

become a pandemic disease recently [9]. The key strategy dealing with this pandemic is to design a rapid detection sensing system with the following features: paper-based, inexpensive, and available everywhere rather than other detection methods. This strategy can help health care systems to have access to a mass screening at the early stages of infection because the main problem creating this horrible situation is the presence of inappropriate detection systems, which can be feasible after the disease manifestations.

\section{Coronavirus}

Coronaviridae is referred to as a family of single-stranded RNA viruses containing $27-32 \mathrm{~Kb}$ positive-sense viral genome covered by a bilayer lipidic envelope and a large number of peplomers or spikes on the surface and about $120 \mathrm{~nm}$ in diameter. This family is a member of Nidovirales order and categorized into 2 subfamilies, 6 genera, 23 subgenera, and about 40 species. Both subfamilies, Coronavirinae and Torovirinae, can involve humans; however, regarding the scale of involvement and morbidity rate, the genera of Coronavirinae subfamily have become more important in comparison with Torovirinae's genera. The Coronavirinae subfamily is also classified into 4 genera, Alphacoronavirus,
Betacoronavirus, Gammacoronavirus, and Deltacoronavirus, among which Alpha- and Beta- are able to infect humans and lead to mild to severe illnesses. SARS-CoV, MERS$\mathrm{CoV}$, and now SARS-CoV-2 belong to the Betacoronavirus genus, having high pathogenic effects on humans, resulting in severe acute lower respiratory tract infections (Fig. 2) [10]. The helical non-segmented RNA of a typical coronavirus encompasses the 5' cap and 3 ' poly(A) tail like a cellular mRNA, which gives rise to the direct translation of viral genome into the functional proteins. Much of the coronavirus genome is made up of its replicase portion (about $20 \mathrm{~Kb}$ ) that ultimately results in the production of non-structural proteins. The remaining one-third of the genome contains genes that produce the virus's structural proteins. At the $5^{\prime}$ end of the helical RNA, a leader sequence is located beside the untranslated region (UTR), which includes several stemloops supporting replication and transcription of the viral genome. Moreover, to control the activity of the structural genes, sequences are embedded at the beginning of these genes, called transcriptional regulatory sequences (TRSs). In general, the formation of a complete coronavirus genome is as follows: 5'-leader-UTR-replicase-Spike (S)-Envelope (E)Membrane (M)-Nucleocapsid (N)-3'-UTR-poly (A) [11].

A complete coronavirus particle is made by the orchestrated formation of $\mathrm{S}, \mathrm{M}, \mathrm{E}$, and $\mathrm{N}$ protein to shape as a 


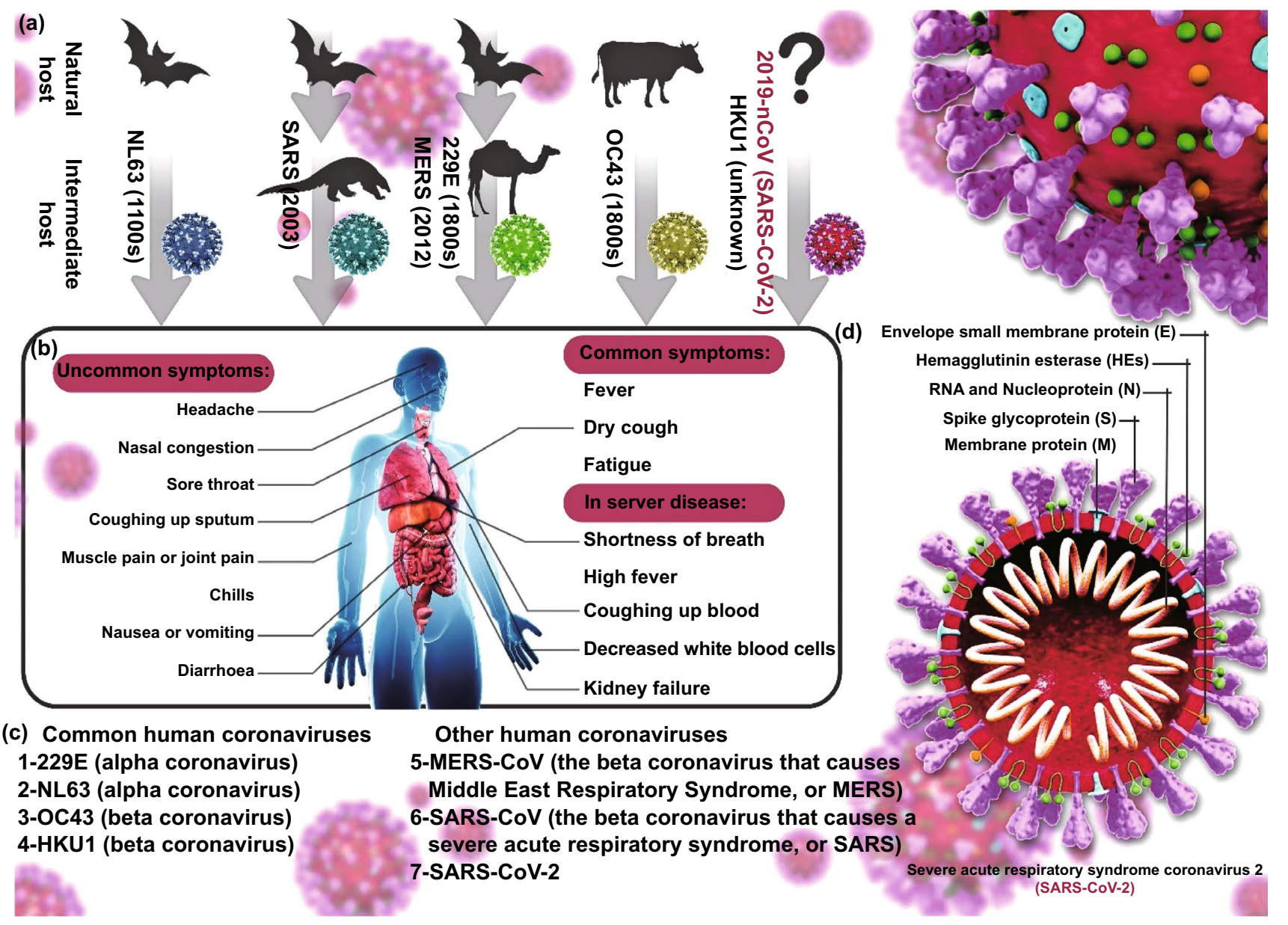

Fig. 2 a Animal (natural and intermediate hosts) origin of human coronaviruses; b clinical presentation of patients with SARS-CoV-2 including common, uncommon, and severe symptoms of SARS-CoV-2. c Human coronavirus types: common human coronaviruses; 229E (alpha coronavirus), NL63 (alpha coronavirus), OC43 (beta coronavirus), HKU1 (beta coronavirus), and other human coronaviruses; MERS-CoV (the beta coronavirus that causes Middle East Respiratory Syndrome, or MERS), SARS-CoV (the beta coronavirus that causes the severe acute respiratory syndrome, or SARS), SARS-CoV-2 (the novel coronavirus that causes coronavirus disease 2019, or COVID-19); d diagram of coronavirus virion structure showing genome(ranges from 26 to 32 kilobases, the largest for an RNA virus) and structural proteins: spike (S), envelope (E), membrane $(\mathrm{M})$, and nucleocapsid $(\mathrm{N})$. N protein forms a complex with RNA and aids in the viral assembly after its replication; S, E, and M proteins create the viral envelope, and $\mathrm{S}$ protein is a club-shaped surface projection, giving the virus its characteristic crown-like appearance on electron microscopy, which is responsible for viral entry into the human cell

spherical and corona solar structure. Once a coronavirus initiates to infect a human cell, the $\mathrm{S}$ protein attaches the viral particle to its host cell, facilitating the uncoating process of the virus and triggering the infection [12]. Peptidases are the main protein used as the receptors of coronaviruses independent of their enzymatic function and domain, for example, SARS-CoV and SARS-CoV-2, as well as HCoVNL63, infect the cells by binding to ACE2 or MERS-CoV while using DPP4 as a way to enter the host cell $[6,13]$. The first need for the virus after binding to its receptor is the proteolytic cleavage of the S protein, which is performed by cellular proteases such as cathepsin and TMPRR 2 in a
$\mathrm{pH}$-dependent manner and results in the fusion of viral and cellular membrane. Following the injection of viral RNA within the cytoplasm, the replicase gene is expressed using the host protein production machine. This gene contains two main ORFs as rep1a and rep1b, which are translated to pp1a and pp1ab polyproteins that subsequently form non-structural proteins (nsps) [14]. Most of these nsps are recruited to shape the replicase-transcriptase complex (RTC) to prepare the proper condition for replication of the viral genome as well as the production of viral structural proteins. Following the replication of viral RNA and synthesizing of structural protein-related mRNA, M, E, and S proteins are produced 
and transmitted into the endoplasmic reticulum (ER), continuing the protein releasing pathway to make endoplasmic reticulum-Golgi intermediate compartment (ERGIC) [15]. Finally, the N protein encapsidates viral RNA, budding into ERGIC, and the mature virion releases from the cell surface where the cell-cell fusion mediates the viral spread lack of any immunity response and neutralization (Fig. 3) [16].

\section{Detection Methods}

Viral infections are among the main causes of mortality and morbidity in humans. Severe clinical manifestations of COVID-19 have urged scientists to find proper detection methods for the SARS-CoV-2 virus at the early stages of the infection. In contrast to other respiratory viral infections, home hospitalization is not recommended for COVID-19 patients with severe symptoms. Regarding the association between the extent of proinflammatory immune responses and the severity of these symptoms [17], which necessitates timely administration of immune suppressor drugs, late detection of this viral infection can enhance the rate of fatality and impose extra economic costs. Besides, the novel coronavirus, SARS-CoV-2, is highly contagious compared to other viruses, especially respiratory ones. The virus is transmitted through droplets upon sneezing, coughing, and less commonly, close contact exhalation [18]. Asymptomatic

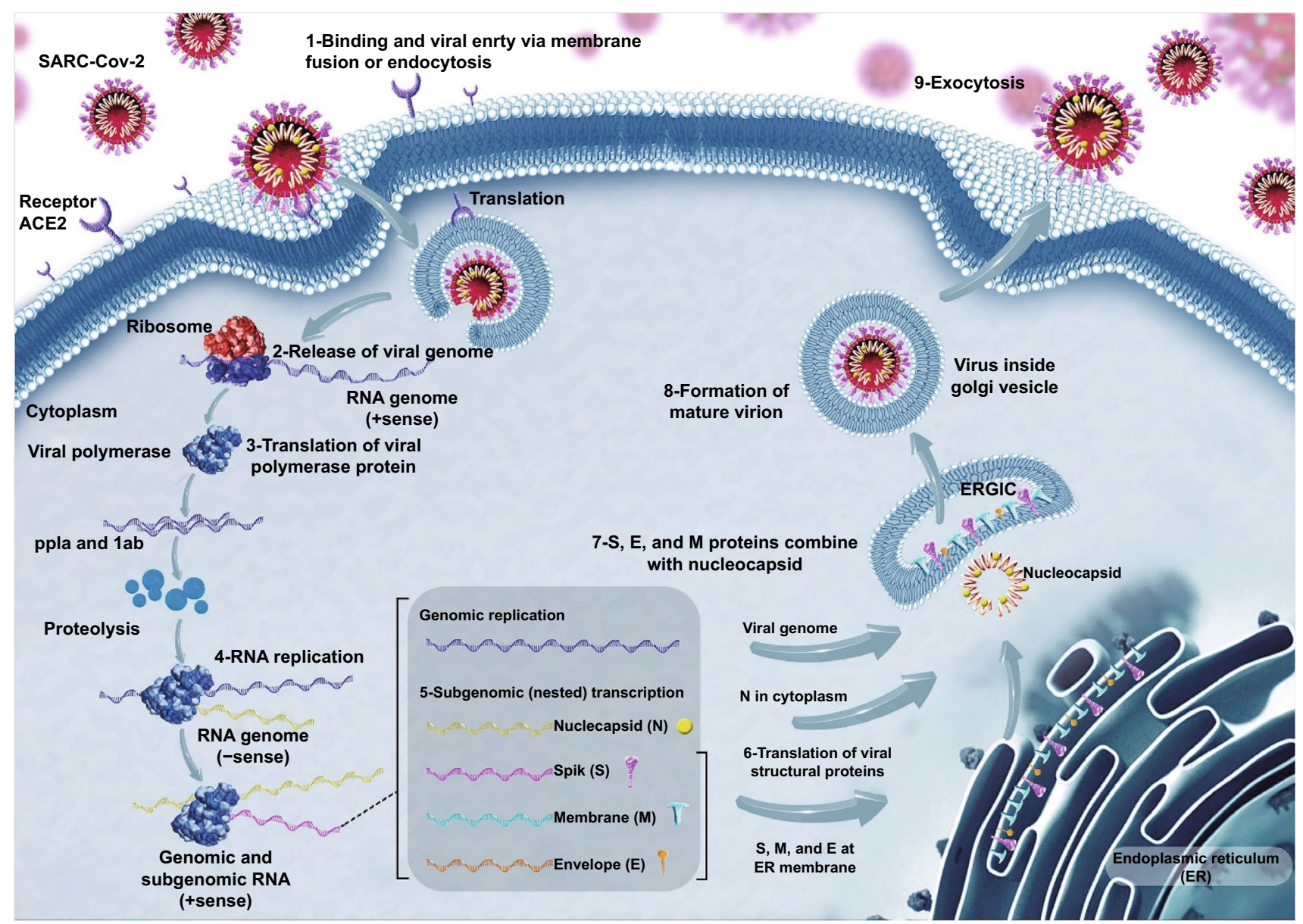

Fig. 3 Schematic diagram showing the replication cycle of SARS-CoV-2. The virus moves into the target cells via an endosomal path. Initially, $\mathrm{S}$ protein connects to the cellular receptor angiotensin-converting enzyme 2 (ACE2) (1). The viral genome is set free (2) and decoded into viral replicase polyproteins pp1a and $1 \mathrm{ab}(3)$; then they are split into small products by viral proteinases (4). Sub-genomic negative-strand templates are created from intermittent transcript on the plus-strand genome and function as patterns for mRNA synthesis (5). The full-length negativestrand pattern is made as a pattern for genomic RNA (6). Viral nucleocapsids are accumulated from genomic RNA and N protein in the cytoplasm (7), followed by budding into the lumen (8), virions are then released from the cell through exocytosis (9) 
carriers of the virus can increase the extent of its transmission. Regarding these unique features of COVID-19, designing specific diagnostic methods for this virus is of particular importance. Early detection of the SARS-CoV-2 virus can hurdle its transmission and help to control the current pandemic. Due to this fact, developing and applying specific and sensitive diagnostic methods for quick detection of the virus is crucial. During the current pandemic and until now, many virus detection techniques have been extensively utilized. These methods include amplifying and sequencing virus-related genes coding, particularly pathogenic proteins $[19,20]$, detecting the virus in host cells lysates [21], etc. However, these approaches have certain drawbacks that limit their usage as routine point-of-care tests. Cultivation of some viruses cannot proceed fast in cell lines, requiring advanced equipment and specialized workforce, and also high costs are some drawbacks of the above-mentioned techniques. Amplification (i.e., polymerase chain reaction (PCR)based) assays are highly sensitive, effective, and economically affordable techniques [22-26]. PCR makes it possible to perform complex and real-time investigations. However, the main problems of this outstanding method are the risk of contamination with foreign nucleic acid sources and nonspecific amplification (if improper primers are selected), which hamper with obtained results. In addition, PCR needs skilled personnel and a good laboratory practice. Finally, requiring several hours to be completed makes PCR difficult to be used for emergency bio-recognition purposes.

Next-generation sequencing [27-31] is a highly sensitive and selective technique for revealing new genomic sequences and is considered as an efficient method for clinical purposes. However, demands for this effective method have slightly diminished due to high costs and needs for complicated equipment. Moreover, good laboratory practice is another requirement for this technique. Immunoassay approaches like enzyme-linked immunoassays (ELISAs) which work based on antigen-antibody interactions, are highly sensitive and much quicker than the above-mentioned techniques. However, requiring specific and high-affinity antibodies (and sometimes expensive recombinant antibodies), especially in the case of complex investigations, has limited their application in routine point-of-care procedures. For solving this problem, low-cost analogs of antibodies have gained much attention in experimental studies.

Sensing and biosensing platforms for detecting viruses [32-36] are considered as ideal and outstanding approaches for providing reliable and alternative solutions for real-time diagnostic and continuous monitoring purposes. In recent years, sensing and biosensing assays have attracted great attention as useful and appropriate tools for point-of-care applications because of their rapid response, high sensitivity, low detection limits, portability, and easy fabrication process $[37,38]$. Various sensing and biosensing platforms for virus detection have recently been developed. Nowadays, regarding the coronavirus epidemic, it is promising to develop a novel and outstanding biosensing method for early and highly sensitive detection of this fatal virus.

In this paper, different traditional and novel pathogen sensing methods, along with the methods for detecting human coronaviruses, have been explained in detail. Among the diagnostic methods discussed earlier in this section, ELISA, real-time PCR, loop-mediated isothermal amplification (LAMP), and chest computed tomography (CT) are of great importance for revealing human coronaviruses. On the other hand, various sensing platforms that can efficiently detect human coronaviruses are classified as sensors, biosensors, immunosensors, and aptasensors. The detection mechanism, advantages, and drawbacks of each of these techniques, which are currently used to identify the new coronaviruses (SARS-CoV-2), will be discussed as briefly as possible (Fig. 4).

\subsection{Chest Computed Tomography (CT) for Detection of Human Coronaviruses}

Chest computed tomography (CT) scan is a kind of radiography and medical imaging using X-ray to figure out any alteration of lung tissue, which sometimes could be helpful to unspecific diagnosis of respiratory viral infections such as coronavirus infection. Regarding the clinical manifestation of COVID-19, CT scan can be used to confirm coronavirus infection as a cause of lung involvement by showing bilateral multilobar ground-glass opacification (GGO) with a peripheral or posterior distribution [30]. A study in Wuhan, China, on COVID-19 patients, showed that CT scans had a sensitivity of about $98 \%$, which is of particular importance compared to a $71 \%$ sensitivity of RT-PCR [30]. The findings of CT scan are usually unspecific and are the same as other types of pneumonia; however, the combination of this imaging with other diagnostic techniques such as real-time PCR or biosensing as 


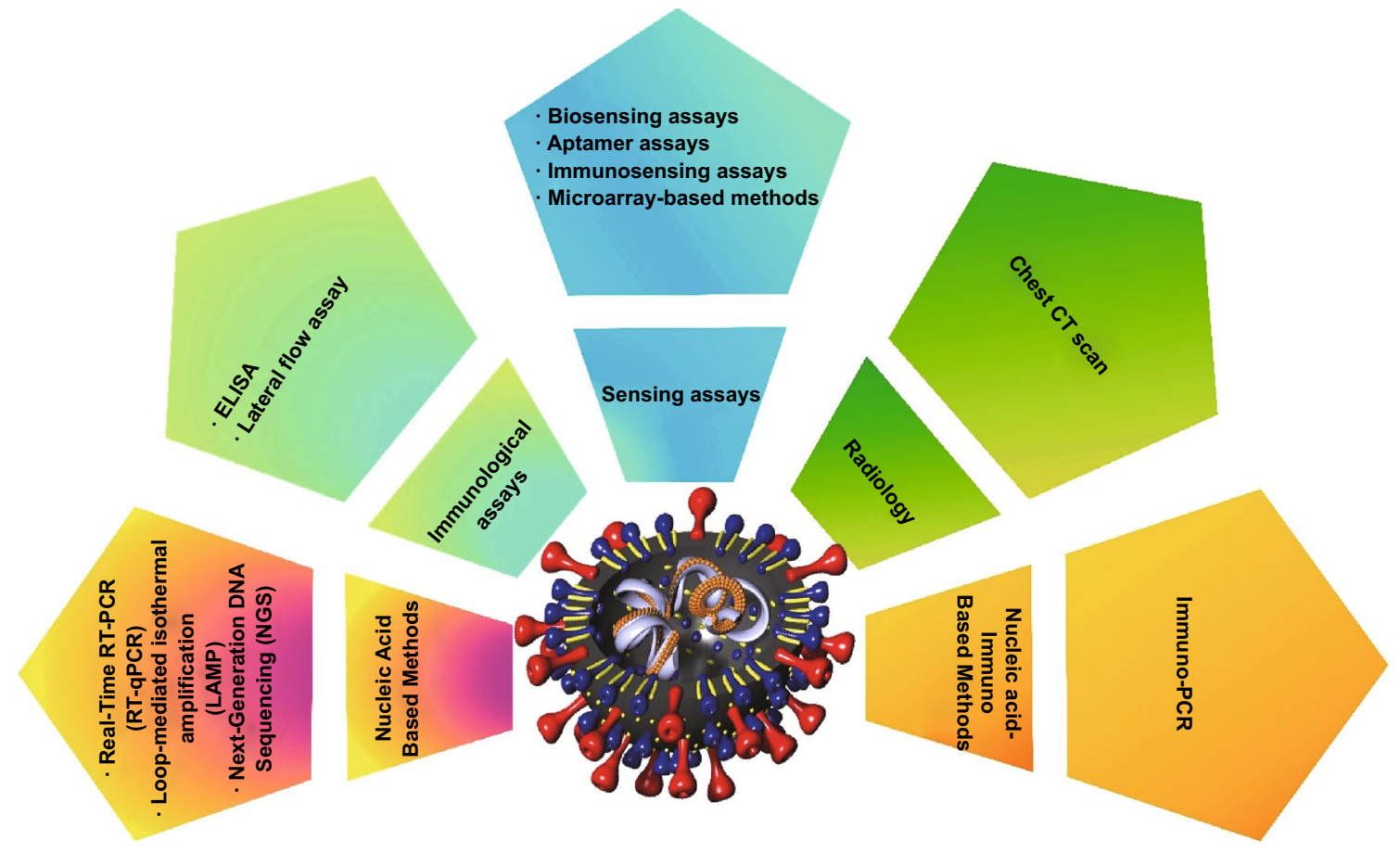

Fig. 4 Overview of different developed techniques for the detection of SARS-CoV-2

the confirmation could be useful to recognize COVID-19 patients.

To overcome the technological limitations (i.e., time-consuming, facility requirement, and laborious process) of the traditional methods such as RT-qPCR and ELISA, an alternative technique should be deployed. When end users can access sensing and biosensing devices, it is recommended to modify available technologies in order to continue working with typical systems rather than replacing new devices. The latest coronavirus catastrophe that occurred in China gave us this opportunity to develop new biosensing and sensing devices capable of meeting the demands of inexpensive and user-friendly systems. Considering the great significance of recognizing various coronavirus types, distinctive methods based on sensing and biosensing techniques (such as sensors, biosensors, aptasensors, and immunosensors), designed for the Coronaviridae family, have been explored in detail in the following sections.

\subsection{Real-Time PCR}

Over the past decades, the nucleic acid-based detection of viruses has been used to identify a specific sequence of the viral genome, confirming the viral infection presumed from the symptoms. In comparison with other types of PCR techniques, real-time PCR has some benefits including elevated speed of the process, decreased cycle time, removing of post-PCR procedures such as gel electrophoresis, and decreased amplicon size as well as the quantizing of virus detection instead of the previous YES/NO format [39]. The quantification of the template by PCR can be done in two ways: relative measurement and absolute measurement. The relative quantity explains the variation in the target sequence rate compared to its level in a related matrix. The absolute quantity expresses the exact number of nucleic acid targets in the sample relative to a particular unit [40]. Depending on the type of viral genome (RNA or DNA), the process of nucleic acid isolation and purification could be varied and have some extra steps. In the term of coronavirus infection, several sequences are used to detect the presence of the virus. For example, to indicate the presence of MERS-CoV infection, the upE sequence (upstream of E gene), ORF1b, and ORF1a are amplified by RT-PCR technique [41] or about SARS-CoV, some universal primer pairs are utilized as follows: COR-1/COR2, BNIoutS/BNoutAs, BNIinS/BNIAs, SAR1s/SAR1as, Cor-p-F, Cor-p-R, and HKU [42]. Recently, following the 
novel coronavirus (SARS-CoV-2) outbreak, several institutes around the world start to share universal primer pairs, which could find SARS-CoV-2-related genes. These genes contained ORF1ab, N, RNA-dependent RNA polymerase (RdRP), E, ORF1b, and S (Table 1) [43]. Despite the accuracy and specificity of real-time PCR testing, this test is time-consuming and also expensive, as well as the need for expert staff [44].

Furthermore, detecting of coronavirus RNA in clinical samples needs professional instruments and RNA extraction and purification kit, because the cellular RNAs are also extracted with viral RNAs which could disturb the amplification and detection mechanism. Thus, this test cannot be utilized as rapid testing. Moreover, regarding the instability of RNA genome and also the method of RNA collection and extraction, the chance of false-negative will increase. Also, the RT PCR test cannot tell if a patient has been exposed to the disease and has recovered, or if they are more likely to get the disease. In addition, the coronavirus can mutate its genes, which might disable the primers to detect their specific targets. However, detection of the conserved regions in the viral genome can ameliorate the rate of problems such as detecting the $5^{\prime}$ UTR region, which is well conserved in most of the coronavirus genes. The other important problem with the detection of coronaviruses by real-time PCR is the normalization of expression because the viral genes are transcripted by RdRP instead of cellular RNA polymerase, while using absolute real-time PCR can solve this problem [45].

\subsection{Loop-Mediated Isothermal Amplification (LAMP) Assay}

To overcome all the technical limitations and laborious detection assays using qRT-PCR, alternative nucleic acidbased method should be deployed. Loop-mediated isothermal amplification (LAMP) is a novel molecular diagnostic

Table 1 Universal primer pairs introduced for the amplification of high pathogenic coronaviruses-related genes [55]

\begin{tabular}{|c|c|c|}
\hline Virus & Sense primer & Anti-sense primer \\
\hline \multirow[t]{2}{*}{ MERS-CoV } & GCAACGCGCGATTCAGTT & GCCTCTACACGGGACCCATA \\
\hline & TTCGATGTTGAGGGTGCTCAT & TCACACCAGTTGAAAATCCTAATTG \\
\hline \multirow[t]{6}{*}{ SARS-CoV } & CACCGTTTCTACAGGTTAGCTAACGA & AAATGTTTACGCAGGTAAGCGTAAAA \\
\hline & ATGAATTACCAAGTCAATGGTTAC & CATAACCAGTCGGTACAGCTAC \\
\hline & GAAGCTATTCGTCACGTTCG & CTGTAGAAAATCCTAGCTGGAG \\
\hline & ССТCTCTTGTTCTTGCTCGCA & TATAGTGAGCCGCCACACATG \\
\hline & CTAACATGCTTAGGATAATGG & CAGGTAAGCGTAAAACTCATC \\
\hline & TACACACCTCAGCGTTG & CACGAACGTGACGAAT \\
\hline \multirow[t]{18}{*}{ SARS-CoV-2 } & CCCTGTGGGTTTTACACTTAA & ACGATTGTGCATCAGCTGA \\
\hline & GGGGAACTTCTCCTGCTAGAAT & CAGACATTTTGCTCTCAAGCTG \\
\hline & GTGARATGGTCATGTGTGGCGG & CARATGTTAAASACACTATTAGCA \\
\hline & ACAGGTACGTTAATAGTTAATAGC & ATATTGCAGCAGTACGCACACA \\
\hline & TGGGGYTTTACRGGTAACCT & AACRCGCTTAACAAAGCACTC \\
\hline & TAATCAGACAAGGAACTGATTA & CGAAGGTGTGACTTCCATG \\
\hline & CGTTTGGTGGACCCTCAGAT & CCCCACTGCGTTCTCCATT \\
\hline & TTCGGATGCTCGAACTGCACC & CTTTACCAGCACGTGCTAGAAGG \\
\hline & CTCGAACTGCACCTCATGG & CAGAAGTTGTTATCGACATAGC \\
\hline & TTGGCAAAATTCAAGACTCACTTT & TGTGGTTCATAAAAATTCCTTTGTG \\
\hline & TCAAGACTCACTTTCTTCCAC & ATTTGAAACAAAGACACCTTCAC \\
\hline & GACCCCAAAATCAGCGAAAT & TCTGGTTACTGCCAGTTGAATCTG \\
\hline & TTACAAACATTGGCCGCAAA & GCGCGACATTCCGAAGAA \\
\hline & GGGAGCCTTGAATACACCAAAA & TGTAGCACGATTGCAGCATTG \\
\hline & AGATTTGGACCTGCGAGCG & GAGCGGCTGTCTCCACAAGT \\
\hline & ATGAGCTTAGTCCTGTTG & CTCCCTTTGTTGTGTTGT \\
\hline & GGTAACTGGTATGATTTCG & CTGGTCAAGGTTAATATAGG \\
\hline & ACAGGTACGTTAATAGTTAATAGCGT & ATATTGCAGCAGTACGCACACA \\
\hline
\end{tabular}


technique for the amplification of DNA with high sensitivity and specificity, cost-effectiveness, high efficiency, and rapidity under isothermal conditions, which is 10 times more sensitive than the conventional PCR. Unlike the conventional PCR carried out with a series of repeated temperature changes and 3-40 cycles, LAMP does not require a temperature cycle and is carried out at a constant temperature $\left(60-65^{\circ} \mathrm{C}\right)$. LAMP uses only a set of 4 specific primers and a DNA polymerase enzyme (for example, a large fragment of Bst DNA polymerase) with replication activity as well as high strand displacement activity, which amplified target genes up to $10^{9}$ copies in less than an hour.

The LAMP technique is also performed to detect RNA sequences using reverse transcriptase (RT) together with DNA polymerase called RT-LAMP [46]. The amplified product could be measured by photometry, visualizing the turbidity resulted from the deposition of magnesium pyrophosphate in solution amplified as a by-product [47]. Any changes in the solution can be seen by the naked eyes or by performing very simple photometric techniques using fluorescence dyes such as SYBR green [48]. This novel technique is widely being used as a powerful alternative POC assay for the detection of viral infections. RT-LAMP is a single-stage nucleic acid amplification method that is functionalized to identify infectious disease resulting from viruses or bacteria; it is also a genetic diagnosis approach utilized extensively to detect viruses, requiring just a single temperature for amplification, and is capable of being completed in less than $1 \mathrm{~h}$ just inside a dry bath. Nowadays, several viruses are detected using LAMP or RT-LAMP methods such as human influenza A virus (as a RNA virus) [49] and herpes simplex virus (as a DNA virus) [50]. Previously, the RT-LAMP method was used to detect high pathogenic coronaviruses such as SARS-CoV in $11 \mathrm{~min}$ at $63{ }^{\circ} \mathrm{C}$ as the reaction temperature, contributing to the rapid diagnosis of this infection through 2003 SARS-CoV outbreak [51]. LAMP method can be a potential candidate for the POC device for the detection of new coronavirus, SARS-CoV-2, and its related morbidity, COVID-19. Abundant studies initiate to design a new RT-LAMP protocol for the detection of this new coronavirus by amplifying a single RNA sequence that is unique in the SARS-CoV-2 in comparison with other coronaviruses. The RT-LAMP protocol designed by Park et al. is reported to be able to detect SARS-CoV-2 RNA with at least 100 copies in a sample. They used $69^{\circ} \mathrm{C}$ as the reaction temperature followed by $95^{\circ} \mathrm{C}$ for $5 \mathrm{~min}$ to deactivate RT and melting curve step. However, 5 regions from
SARS-CoV-2 were selected to be amplified by this protocol as 2 regions of nsp3, 2 regions of $S$ gene, and 1 region from Orf8; nsp3 region amplification demonstrated more sensitivity than other regions. The other beneficial aspect of this study was low period of reaction (30 min after beginning) [52]. Lamb et al. in the USA defined a new RT-LAMP protocol to detect causative agent of COVID-19, taking much less time up to $30 \mathrm{~min}$ and $63{ }^{\circ} \mathrm{C}$ for reaction temperature [53]. This new protocol seems to be more affordable, accelerating the detection procedure as well as facilitating the detection, which could make this protocol more reliable than others. The next detection of SARS-CoV-2 was performed by Lin Yu's team, who designed an RT-LAMP protocol with less detection time up to $15 \mathrm{~min}$ [54]. Altogether, the most important benefits of the LAMP technique are its lesser affording and eliminated time-consuming process as well as the need for constant temperature which omits the thermocycler step, the most essential step in the PCR technique. In addition to its advantages, LAMP technique also has some limitation restricting its use, for example, this technique is less used than PCR and is utilized only in clinical identification processes to initiate appropriate treatment time; so, PCR cannot be substituted for biological processes with research purposes such as cloning [55]. Because the LAMP technique uses primer sets (between four and six numbers) and targets several regions of a single piece of DNA or RNA, the design of these primers requires high ability and advanced tools and software that are much more time-consuming and difficult than the PCR technique. Other limitations of LAMP include the need to use primers with degenerated sequences to detect infections, especially with viruses of different types, which can only be feasible by using PCR testing as the diagnostic technique. The large number of primers for each target in the LAMP technique greatly increases the likelihood of primer-primer interactions during this test procedure, which can have a significant effect on the specificity of the test compared to PCR. Another major drawback and limitations of the LAMP technique is the serial presence of DNA products, which causes several bands to emerge after the gel electrophoresis step rather than having a band on the gel, making it difficult to detect each band [56].

\subsection{ELISA}

For many years, immunological assay, particularly ELISA, is used to detect viral antigens or antibodies against viral antigens in order to assess the rate of viral infection or vaccine 
efficiency. In fact, the ELISA test is based on the interaction between antigens and the antibodies using an enzyme to visualize and transform the reads in a measurable way. So far, several ELISA methods have been defined based on the material coated at the bottom of plates or the way of measuring the absorbance and exact concentration. These methods are direct ELISA, sandwich ELISA, competitive ELISA, and reverse ELISA [57]. Accomplishing a perfect ELISA test needs at least one antibody specified to detect an antigen which is coated at the bottom of a microtiter plate. Moreover, this test is utilized to measure the amount of specific antibodies in the samples by using a microtiter plate coated with the complement antigen (Fig. 5). Measuring the amount of the desired antigens or antibodies is done by the combination of colorimetric and spectrophotometric in the ELISA test [58].

Given the ability of immune cells to produce antibodies, a person who gets infected with a kind virus initiates to express specific antibodies in his/her circulation, which could be measured by ELISA testing. Depending on the type of antibody, the phase of each viral infection is estimated as, if such antibodies are $\operatorname{IgM}$, they refer to the acute infection and, if they are $\mathrm{IgG}$, they refer to chronic or previous infection [59]. The identification of MERS-CoV from the patient serum using the ELISA technique was feasible by detecting $\mathrm{N}$ or S protein-specified antibodies [60]. Moreover, the immune detection of coronaviruses is also utilized to find SARS-CoV and SARS-CoV-2 [61, 62]. Since this test is performed on the patient serum, one of the major problems with the ELISA test is that coronavirus infection is a local type of viral infection and mostly involves the mucosal immunity of the individual.

Current IgM and IgG kits of coronavirus have intact on coronavirus, which should infect laboratory technicians. Also, the presence of $\operatorname{IgM}$ and $\mathrm{IgG}$ in the serum of asymptomatic patients is detectable after 7 and 14 days after being exposed to a virus means that the patient would carry a virus while the kit cannot detect it (Fig. 6). Therefore, until the submission of this paper, there is no test for the identification of virus antigens in the serum of patients. In general, there are several problems with this test, which make it inappropriate in some cases. These problems include false negative, noise reaction made by samples, unspecific reaction because of improper plate washing, time-consuming, the difference between reagent concentration in prepared ELISA kits, being expensive, and the need for expert staff with the skill of triggering immunoassay, working with ELISA reader and other related devices, and calculating the exact amount of antigens or antibodies [67, 68]. Taken together, these problems highlight the need for a more efficient alternative approach with a lower sampling rate.

\subsection{Sensing Methods}

Sensors are outstanding analyzing tools which reversibly and selectively interact with a specific analyte and convert an input measurable chemical parameter to the concentration of a particular compound and an analyzable electrical response [69-73]. The chemical information is produced following the attachment of a chemical compound, biomaterial, or a combination of both to the surface of a physical transducer toward the analyte (Fig. 7).

Up to now, various sensors have been advanced for the detection of diverse kinds of viruses such as human coronavirus [74-77], HIV [78, 79], hepatitis B virus (HBV) [80], hepatitis C virus (HCV) [81], and Zika virus [82, 83].

There has been a growing concern in recent years in the application of sensing systems in the detection of infectious
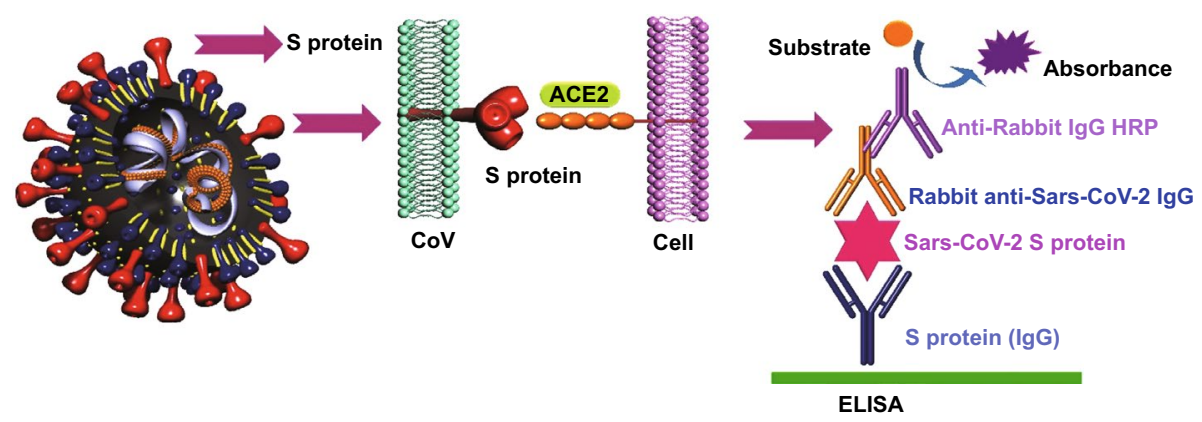

Fig. 5 Overview of ELISA techniques for the detection of SARS-CoV-2 


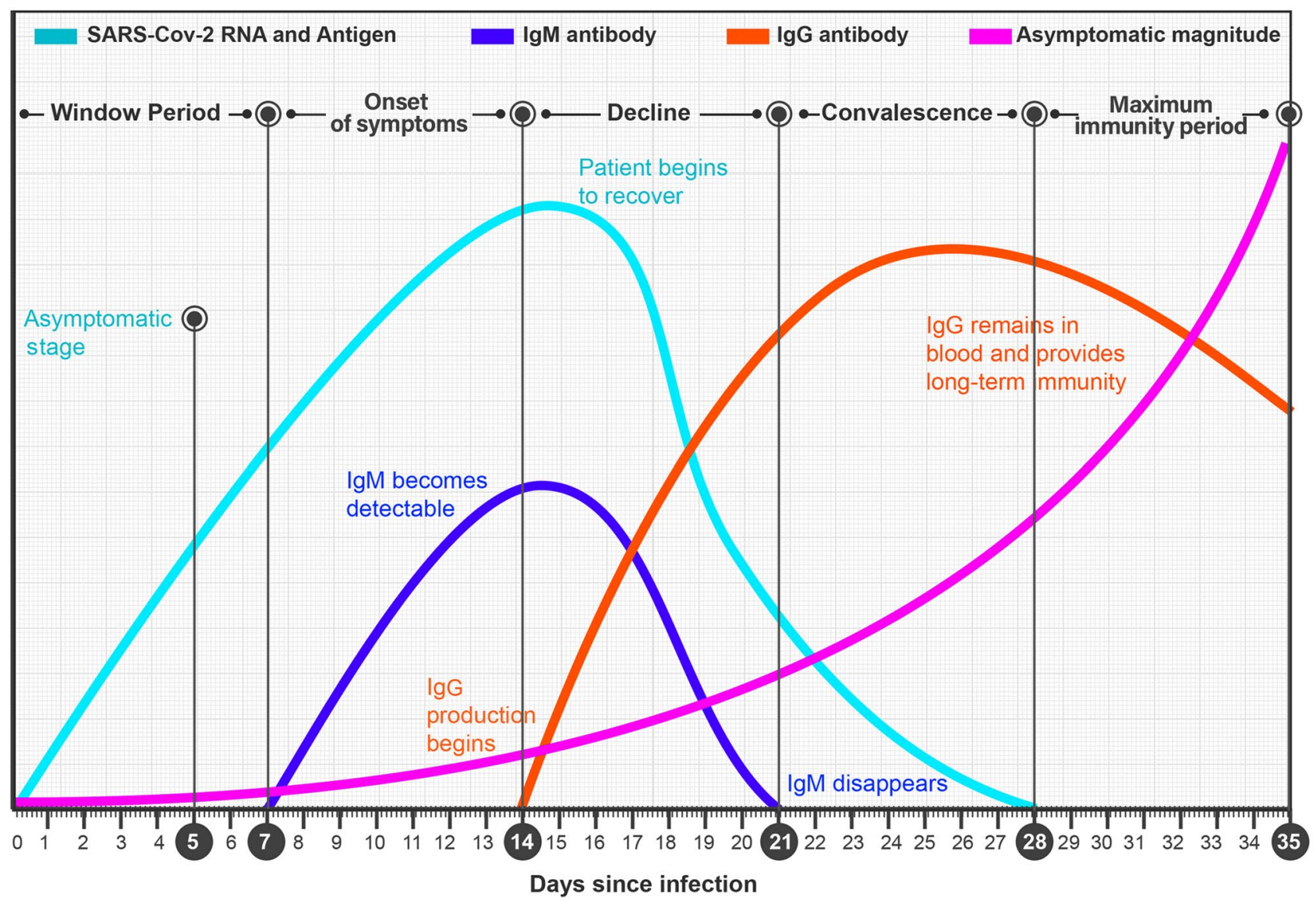

Fig. 6 Based on the unsatisfactory efficiency of COVID-19 kits due to the detection lag of 7 and 14 days for appearing IgM and IgG in the serum of asymptomatic patients, porters would not be recognized, triggering the spread [63-66]
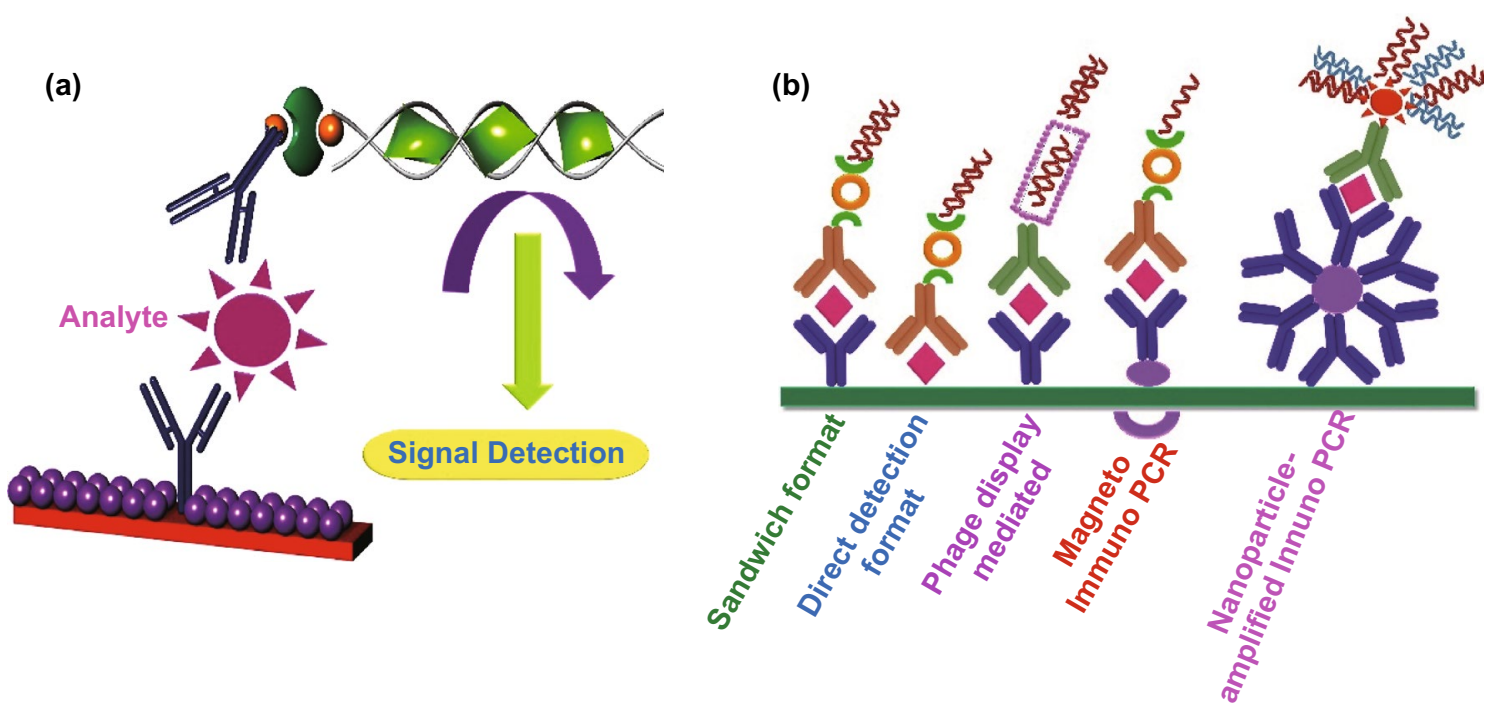

Fig. 7 a Immune-PCR, the immuno-PCR arrangement begins with a safe assay followed by PCR. Immuno-PCR is parallel to ELISA with the exception that terminal DNA is augmented by a PCR; $\mathbf{b}$ different immune-PCR platforms available, immuno-PCR, the sandwich setup of immuno-PCR, the direct setup of antigen detection, phage intermediated where single-chain variable fragments (scFv), magneto immuno-PCR, nanoparticle-amplified immune PCR. Redrawn from Ref Front Microbiol. 2019; 10: 1957 [67] 
diseases. Microcantilever-based sensors with high sensitivity are currently being developed for the discovery of contagious microorganisms like bacteria, fungi, and viruses. Microcantilevers have emerged as a unique platform for sensors with on-chip electronic circuitry and high sensitivity. The selectivity and specificity of the microcantilever-based sensors can be achieved by the generation of a functional layer on the surface of the microcantilevers by coatings or covalently binding of recognition elements for the detection of targets. In microcantilever-based sensors, cantilever bending induced by differential surface stress is produced when the molecular adsorption is confined to one surface of the cantilever. Microcantilever- based sensor has been used for the detection of SARS-CoV, using feline coronavirus (FIP) type I virus. This microcantilever-based sensor is capable of recognizing (FIP) type I virus with the help of a microcantilever coated by the FIP type I anti-viral serum containing antibodies. The limit of detection was equal to $0.1 \mu \mathrm{g} \mathrm{mL}^{-1}$ for the sensor, and the time of analyzing assay was less than $1 \mathrm{~h}$. Under no circumstances, it would be deduced that the mentioned microsensor is capable of being used to recognize SARS-CoV and FIP I virus in a single and quick test at present, but such outcomes signified that deflecting microcantilevers can sense the coronavirus. This study provides a path to develop the microcantilever sensors for human-related SARS-CoV [84].

The piezoelectric flexural plate wave (FPW) is one of the ultra-sensitive point-of-care promising diagnosis devices with high sensitivity, which can measure the mass of a vibrating element. These microdevices are often created by forming the transducer on the surface of a material or over a substrate with piezoelectric properties [85]. For the detection of SARS-CoV, a potable miniature FPW system developed. Human angiotensin-converting enzyme 2 (hACE2) was employed as a functional receptor for the creation of functionalized FPW biosensor for the detection of SARS S protein. Figure 8 shows the sensor chip for the flexural plate wave-based identification system for SARS coronavirus [86].

Developing the uncomplicated colorimetric and fluorescent assays, which make point-of-care RNA and DNA recognition possible, was the subject of an important study. A colorimetric paper-based assay has been developed for the detection of DNA based on pyrrolidinyl peptide nucleic acid (acpcPNA)-caused nanoparticles aggregation for the screening of MERS-CoV, MTB, and HPV viruses. AgNPs have been utilized as the colorimetric reagent to detect cDNA on the basis of acpcPNA-caused nanoparticle accumulation.
Peptide nucleic acid was used as a probe due to its outstanding properties such as high chemically and biologically stable and effective hybridization with complementary DNA strands. The designed acpcPNA probe has a lysine at C-terminal, which gives a positive charge of the probe. In the absence of complementary DNA, the positive charge of the acpcPNA probe leads to aggregation of citrate anion-stabilized silver nanoparticles (AgNPs), while in the presence of the complementary target, DNA and creation of the anionic DNA-acpcPNA duplex lead to electrostatic repulsion. This repulsion causes the dispersion of aggregated AgNPs and, as a result, leads to a detectable color change. The concentration of target oligonucleotide is related to the color change of AgNPs, giving limit of detection $1.53 \mathrm{nM}$ for MERS-CoV. The presented colorimetric DNA sensor based on paper can be used as an alternative method for the selective, sensitive, rapid, and simple assay for MERS-CoV cDNA (Fig. 9) [87].

Nanoparticles present highly sophisticated specifications that allow them to be a part of any novel and promising biological innovation. For example, their size and shape can be modified, and their large surface provides a platform for incorporating various chemical groups as available binding sites [90]. Because of this, it is possible to alter the biological function of these nanomaterials toward the site detecting of target molecules through multiple interactions and actively targeted imaging for sensing and diagnosis of viral infections [88]. The most common metal nanoparticles that have been used to treat viral infection or their detection are silver NPs [89], gold NPs [90, 91], silica and mesoporous [88, 92-94], carbon nanotubes [95, 96], iron oxide NPs [97], etc.

\subsection{Biosensing Assays}

In general, biosensors $[98,99]$ are ideal devices for analytical purposes. These valuable tools employ a combination of a specific biological element and a transducer to determine a certain analyte in any biological sample with high sensitivity. Biosensing assays can be categorized according to the types of transducers and bioreceptors. Enzymes [100, 101], nucleic acids (DNA or RNA) [102], antibodies (monoclonal, polyclonal, and recombinant) [103], proteins [104, 105], biomimetics (aptamers and molecularly imprinted polymers (MIPs)) [102, 104, 106], and microbial cells [106] are the main groups of bioreceptors that can be employed to detect 

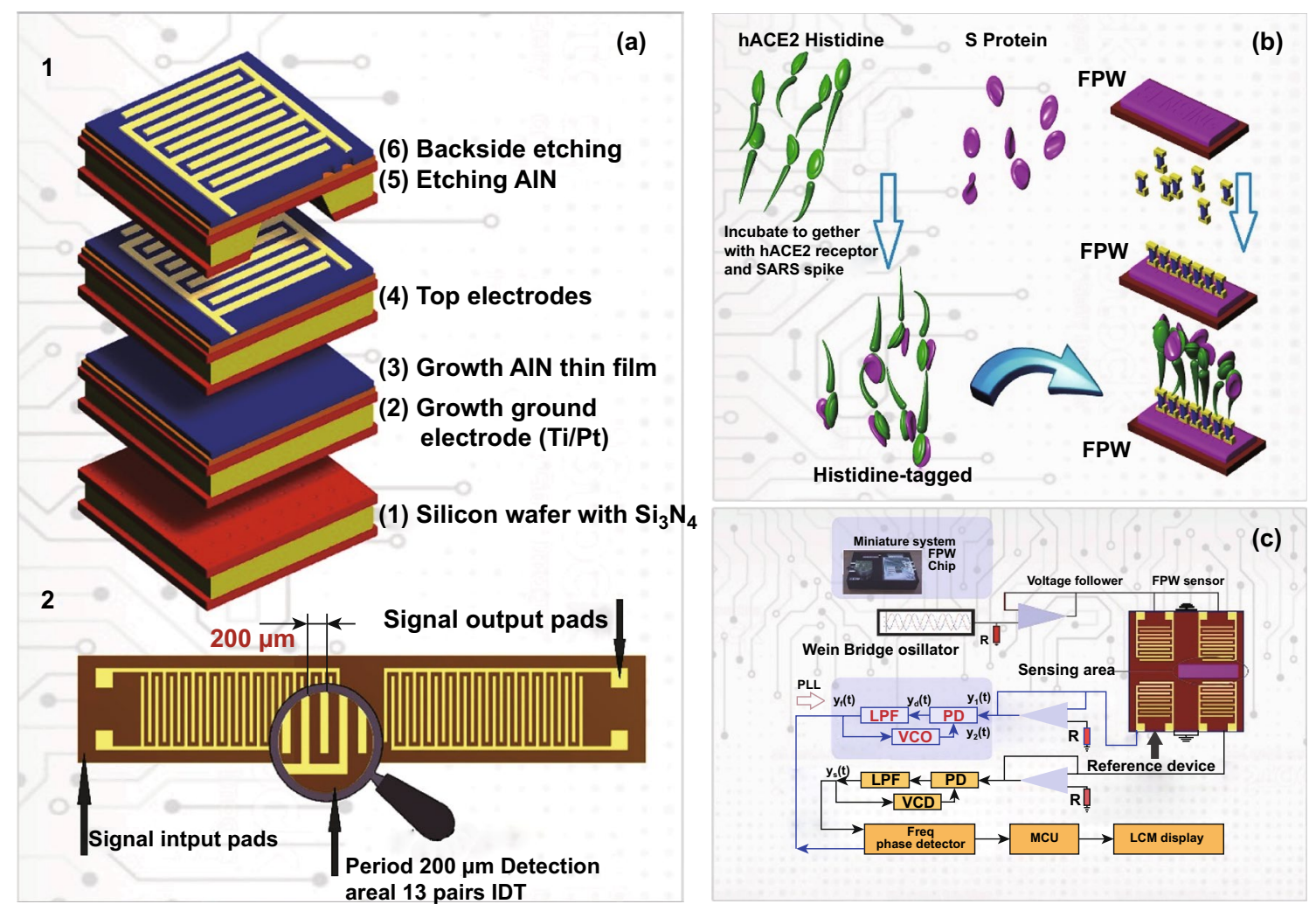

Fig. 8 a Sensor chip for flexural plate wave. (1) Process of microfabrication with the help of technologies of microelectromechanical systems. (2) Top view image of flexural plate wave where the IDT period is equal to $200 \mu \mathrm{m}$ along with 13 pairs and $1.6 \mu \mathrm{m}$ is approximately considered for the total thickness. b Diagram of immobilization process represents the fact that an anti-SARS transfer to the sensor system with immobility by the hybrid protein of S-hACE2 can provide phase shifts because of utilizing hACE2 and including the protein S to the functionalized biosensor of flexural plate wave (FPW). c Control procedure of the FPW related to the combined minuscule arrangement for sensing and biosensing purposes. The FPW sensing framework system was constructed of a voltage follower, an FPW device, a Wien bridge oscillator (WBO), and a phase-locked loop (PLL) that consist of a phase detector (PD), low-pass filter (LPF) and voltage-controlled oscillator (VCO), a frequency phase detector, a liquid crystal display module (LCM) display, and a microprocessor. Adapted from Ref. (MCU) [86]

various pathogens, especially human coronaviruses. Moreover, another significant part of a biosensor is the transducer, which efficiently transforms the physical and chemical alterations related to the bio-recognition event into quantifiable electrical responses. The transducers can be electrochemical, optical, gravimetric (mass-sensitive), and thermometric (calorimetric) [107, 108]. Currently, electrochemical biosensors are applied for highly sensitive determination of different classes of viruses, including human coronavirus, HIV, HBV, HCV, and dengue virus. These biosensors (i.e., potentiometric [109], amperometric [110-112], and conductometric [113]) play significant roles in various biosensensing fields because of their facile fabrication, small size, facile interpret results, robustness, and low detection and quantification limits. In potentiometric biosensors, a bioreceptor and a transducer are combined for detecting changes in the concentration of ions, and consequently, in these biosensors, the obtained analytical response reflects the concentration of the target analyte. Amperometric biorecognition assays record current alterations at a particular potential during a constant time. The changes of the current are directly associated with the concentration of the target analyte. Conductometric or impedimetric biosensors are considered as effective electrochemical biosensing platforms in which the alterations in the conductivity of a solution are recorded. Another type of biosensors that are commonly utilized for detecting viruses, especially human coronaviruses, includes optical biosensors. They are the highly sensitive, selective, and rapid and have low limits of detection (LODs) and quantification (LOQs). Furthermore, they allow for real-time monitoring of the measurement process. The mechanism of these interesting biosensors is 


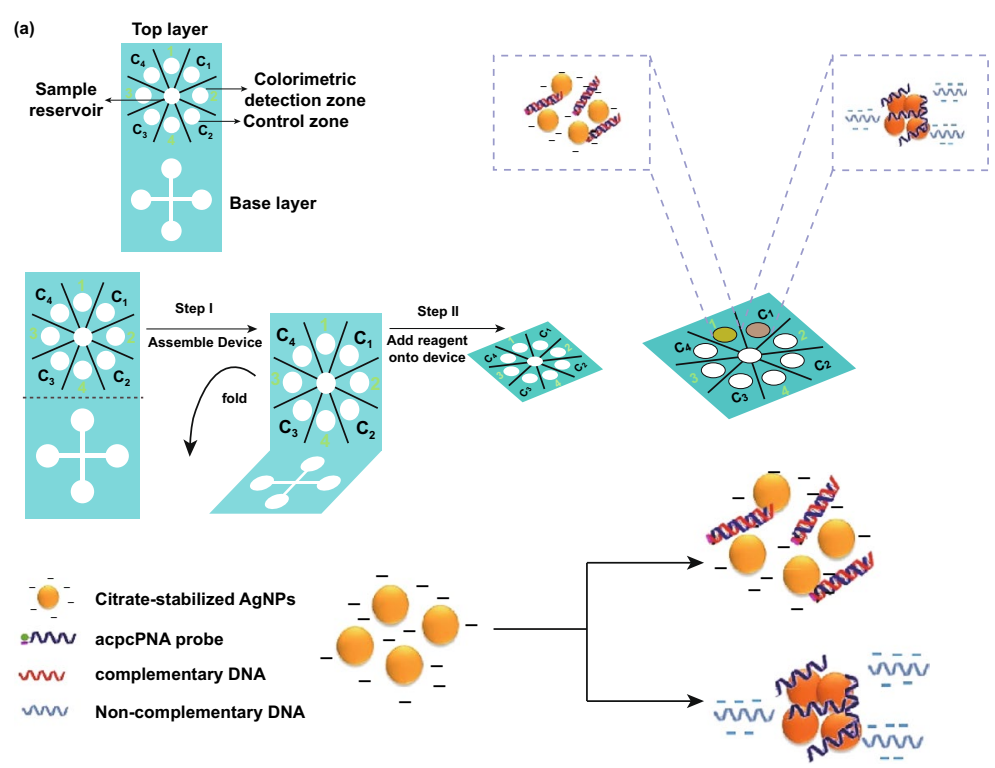

(b)

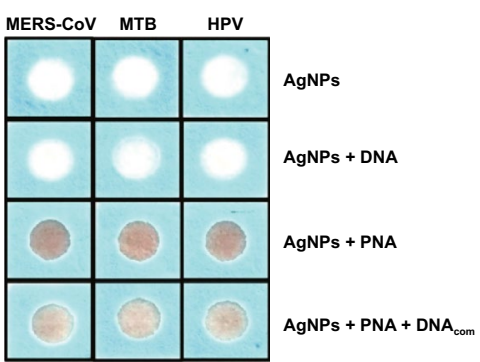

(c)
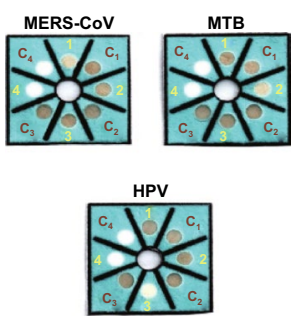

Fig. 9 a Designing and b photograph of visual color alterations got from the recognition of 205 HPV, MTB, and MERS-CoV in the DNAcom presence. After acpcPNA addition, the yellow AgNPs turned red. The color also turned red because of AgNPs aggregation when the solution consists of the DNAnc and acpcPNA. On the other hand, altering the color from red (aggregation state) to yellow (non-aggregation state) in DNAcom presence, the intensity dependence on the DNA concentration is clear. c Selecting $100 \mathrm{nM}$ MERS-CoV, MTB, and HPV recognition with the help of a multiplexed colorimetric sensor. Adapted from Ref. [87]. (Color figure online)

based on the principle of sensing alterations with the dimensions of photons or light. Various kinds of optical biosensors that have been investigated for different viruses, especially human coronaviruses, are plasmon resonance (SPR) [114], ellipsometric and reflectometric interference spectroscopy (RIfS) [54, 115], colorimetric [54, 116], fluorescent [117], and surface-enhanced Raman scattering (SERS) [118, 119]. Among these optical biosensing assays, SPR biosensors are of great importance as they can directly measure the alterations happening in the refractive index of light on the sensor surface, reflecting the analyte concentration. In the following paragraphs, various types of the above-mentioned electrochemical and optical biosensors used for highly sensitive determination of human coronaviruses are discussed.

For the improvement in the sensitiveness of traditional immunoassay tools and rapid and accurate detection of SARS-CoV in the early stage of infection, a sandwich localized surface plasmon coupled fluorescence (LSPCF) fiberoptic biosensor was applied for the detection of SARS $\mathrm{N}$ protein. It has been shown that this protein expressed in the early stage of infection could be detected only 1 day after infection; therefore, it could have diagnostic value and disease monitoring. The LSPCF is excited by localized surface plasmon, where the evanescent field is applied near the core surface of the optical fiber. At the same time, the detection of the fluorescence signal is performed by a photomultiplier tube located beside the optical fiber with high collection efficiency. The LSPCF fiber-optic biosensor demonstrates a capacity for recognizing especially small concentration $\left(\sim 1 \mathrm{pg} \mathrm{mL}^{-1}\right)$ of SARS-CoV N protein in serum [120].

An SPR (surface plasmon resonance)-based biosensor as a real-time and label-free detection system was introduced for rapid and high-throughput detection of SARS coronavirus. The SPR biosensor was devised for the detection of a respiratory virus-specific oligonucleotide in an SPR biochip. To improve the sensitivity of the developed biosensor, PCR primer was labeled by biotin and utilized to increase the signal by introducing streptavidin following hybridization. Throat swab samples infected by nine common respiratory, including SARS, were tested by the inventive SPR-based biosensor to estimate the specificity, duplicability, and sensitivity of this technique. The findings suggest that the use of a high-throughput gene biochip combined with the SPR technique has the capability to be applied for the effective and swift identification of SARS-CoV among nine common respiratory usual viruses [121].

Detection of specific antibodies, including $\operatorname{IgM}$ and $\mathrm{IgG}$ of SARS in the blood of infected patients, could be used 
for highly sensitive, fast, and simple diagnosis methods for the rapid detection of this virus. AMPs (antibody mimic proteins) are polypeptides that attach to their target analytes with great attraction, selectivity, and particularity, just similar to typical antibodies; however, their size is smaller than 2-5 $\mathrm{nm}$ and less than $10 \mathrm{kDa}$, and in contrast with usual antibodies, they show high stability to electrolyte concentrations and a wide range of $\mathrm{pH}$. Nanowire biosensors based on AMP (fibronectin, Fn) as a capture agent with a high binding affinity for nucleocapsid $(\mathrm{N})$ protein have been introduced for the detection of SARS-CoV. This protein is highly antigenic and might be a suitable diagnostic biomarker. The results of this study show that $\mathrm{N}$ protein could be detected at sub-nanomolar concentration short response time $(\sim 10 \mathrm{~min})$ and without any labeled reagents as a signal amplifier when compared to the long time ( $\sim$ hours) required to achieve a result from other diagnostic technologies such as qRT-PCR and ELISA methods and without any required multistep analysis. This report shows the capability of fabricated nanobiosensors for being used as a precise, suitable, and rapid means for detection of $\mathrm{N}$ protein as SARS-CoV infection biomarker (Fig. 10) [122].

Another SPR-based biosensor was developed for easy detection of SARS employing a recombinant protein made
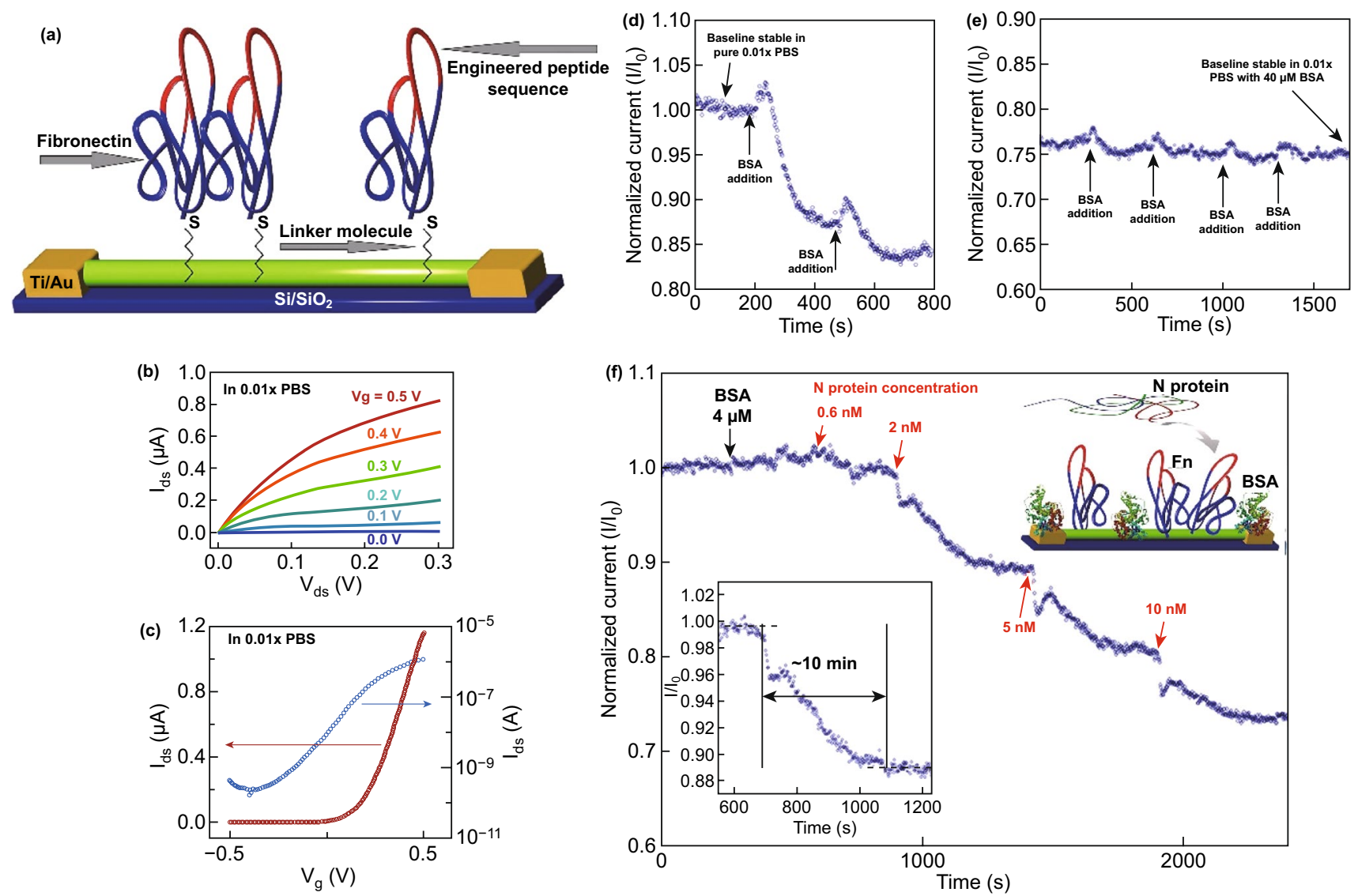

Fig. 10 a Schematic presentation of immobilized Fn on the exterior part of an $\operatorname{In}_{2} \mathrm{O}_{3}$ nanowire FET apparatus device. The areas of Fn are highlighted in red with the plotted peptide sequence. Fn was connected to the related nanowires through the cysteine sulfhydryl group near the C-terminus, distant from the binding location. b Curves pertinent to a family of $I_{\mathrm{ds}}-V_{\mathrm{ds}}$ and $\mathbf{c}$ a typical $I_{\mathrm{ds}}-V_{\mathrm{g}}$ curve (plotted both in logarithmic (blue)) and linear (red) achieved from one of our instruments functioning with the aqueous gate arrangement. Normalized electrical output $\left(I / I_{0}\right)$ versus time of a single functioning instrument. d-e Demonstrating the response curves to passivation upon the addition of consecutive aliquots of BSA. Upon increasing the BSA concentration (from pure $0.01 *$ PBS), the baseline re-equilibrates at lower values of S-D current until stability is finally reached at $40 \mu \mathrm{M}$ BSA, in $0.01 *$ PBS. f Showing response for a nanowire device utilized with Fn. The red arrows show the times when the solution was increased to a specified concentration of $\mathrm{N}$ protein. The inset on the right side is the arrangement of our device through active sensing measurements. BSA protein was used to block sites for nonspecific binding. The Fn probe molecule was then used to specifically capture the target $\mathrm{N}$ protein. The inset on the left side is to show the plateau and the definition of response time. Adapted from Ref. [122]. (Color figure online) 
by genetically fusion gold binding polypeptides (GBPs) to a SARS coronaviral surface antigen (SCVme). The fusion protein offers an easy and actual method for the fabrication of SPR sensing platforms, allowing precise and careful detection of the anti-SCVme antibody. In this fabrication, the GBP domain with high gold binding affinity serves as an anchoring part onto the gold surface, and the SCVme domain acts as a recognition ligand for the detection of anti-SCVme antibodies. SPR analysis indicated that fusion protein self-immobilized onto the gold surface simply and strongly, via GBP, without complicated surface chemical modification, offering a particular sensing platform with high stability for anti-SCVme diagnosis. The desired packing density of the fusion protein to the SPR chip was realized at the concentration of $10 \mu \mathrm{g} \mathrm{mL}{ }^{-1}$; this density presented the best diagnosis response (906 RU) for anti-SCVme. The fusion protein-coated SPR chip at the most favorite packing density had a lower LOD of $200 \mathrm{ng} \mathrm{mL}^{-1}$ anti-SCVme in $10 \mathrm{~min}$ with high selectivity detection in the presence of nonspecific mouse IgG as the negative control (Fig. 11) [123].

Today, biosensors can be prepared and modified using nanotechnology and applying a range of nanomaterials to improve the specificity and sensitivity of the detection of biomolecules. This is feasible because nanomaterials can upgrade optical and electrochemical functions of biosensors. Furthermore, the detecting capability, selectivity, efficiency, and specificity of biosensors can be improved by designing and incorporating immobilized bioreceptors, which also deliver a more potent signal amplification process, especially when detecting viral particles. By these modifications, we can expect that biosensor-based instruments to soon be used (a)

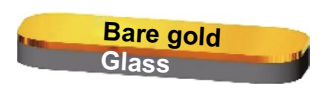

(b)
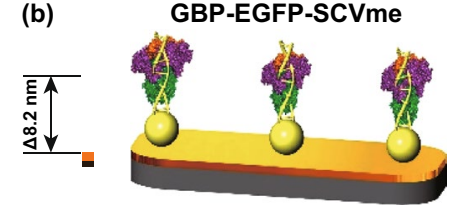

(c)

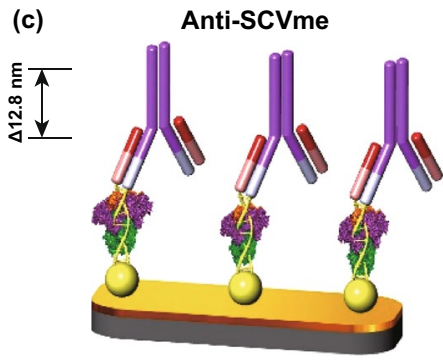

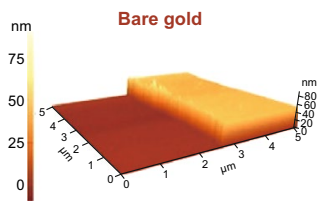
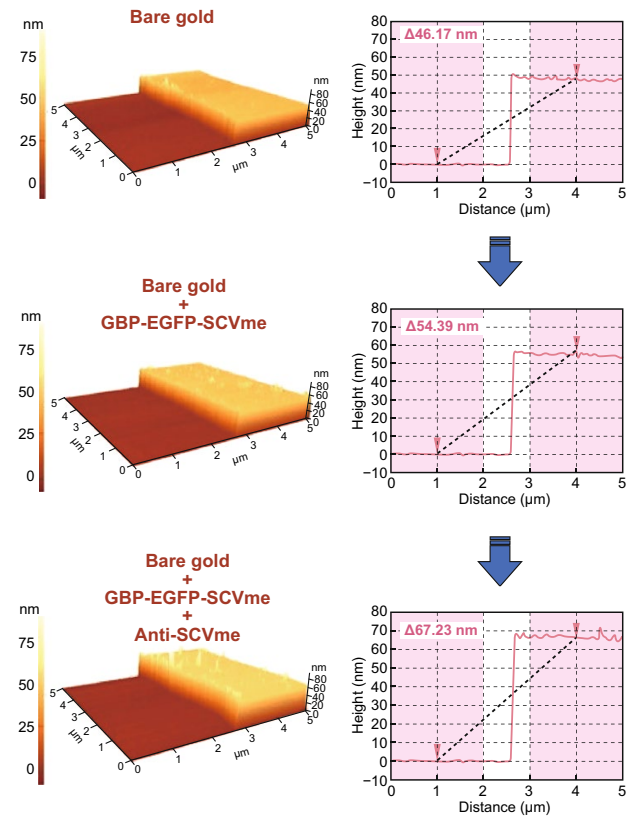

(d)

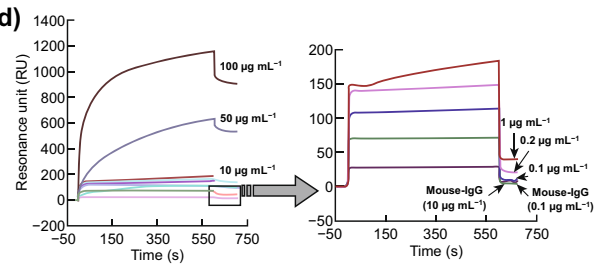

(e)
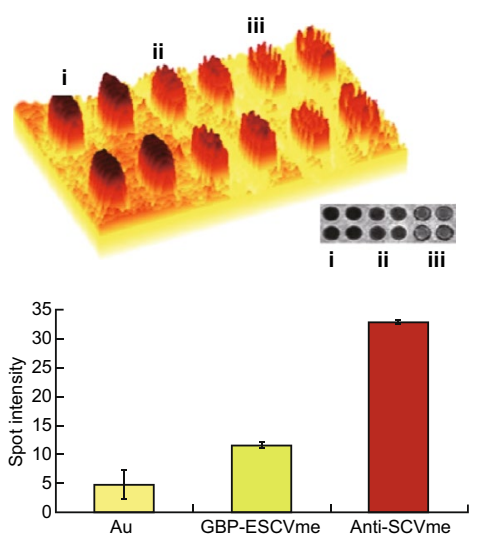

Fig. 11 AFM pictures of the consecutive binding of anti-SCVme on the gold-micropatterned surface and GBP-E-SCVme. a Bare Au surface, b immobilizing of the GBP-E-SCVme fusion proteins onto the gold surface, and c consequent connection of the anti-SCVme antibodies on the GBP-E-SCVme layer. Left, schematic of consecutive binding of GBP-E-SCVme and anti-SCVme on the gold micropatterns; middle, threedimensional topological images; right, the cross-sectional contours of samples a-c, sequentially (these are average height differences of the individual scan lines from each area). d SPR sensorgrams for (1) sensitive and (2) selective recognition of anti-SCVme utilizing the GBP-ESCVme-imbedded gold sensor chip at different concentrations $\left(0.1,1,10,50\right.$, and $\left.100 \mu \mathrm{g} \mathrm{mL}^{-1}\right)$ of anti-SCVme and $\left(1\right.$ and $\left.10 \mu \mathrm{g} \mathrm{mL} \mathrm{m}^{-1}\right)$ of mouse IgG as negative controls. SPRi analysis of the sequential binding of GBP-E-SCVme and anti-SCVme onto gold micropatterns composed of 50-nm-diameter circles. e Three-dimensional and two-dimensional (inset) images of bare gold micropatterns as controls (sample (i)); binding of GBP-E-SCVme fusion proteins onto the gold patterns (sample (ii)); and successive binding of GBP-E-SCVme and anti-SCVme onto the gold patterns (sample (iii)). Spot intensities of the three samples shown in scanned images were measured through the gold circle micropatterns. Adapted from Ref. [123] 
as portable (as they can be very smaller in size than currently available equipment) and affordable (implementing less, cheap, and novel materials) devices at clinical setting [88]. Overall, there is still room for improving the applicability of biosensors for detecting human viruses, in particular coronaviruses, warranting more studies in this field [124].

The biosensor-based method upon imaging ellipsometry was used directly to identify two neutralizing monoclonal antibodies and serial serum samples. Ellipsometry is an optical method for determining the dielectric characteristics (dielectric function or complex refractive index) of thin films. Ellipsometry is based on measuring the alteration of polarization upon transmission or reflection, comparing it to a model. It can be used to characterize thickness (depth), roughness, composition, doping concentration, electrical conductivity, crystalline nature, and other material features. It is very sensitive to the alteration in the optical response of radiation that interacts with the material being examined. As a label-free technique, the biosensor based upon imaging ellipsometry showed a more proficient tool for measuring serum samples from SARS patients and the affinity between these antibodies and the SARS coronavirus [125].

\subsection{Immunosensing Assays}

Immunoassays are bio-analytical approaches in which the interaction of an analyte (i.e., antigen) and an antibody is the basis of the measuring of a specific analyte $[126,127]$. In this regard, an immunosensing assay is designated as an analytical method in which antibodies or antibody parts are used to recognize biomolecules. These assays are frequently applied in different industrial fields such as pharmaceutical, agriculture, and food industries, as well as for biological threat management, epidemic diseases control, and clinical and diagnostics purposes. The produced signal in immunosensing assay is directly related to the rate of antigen-antibody binding events [128-130]. In this regard, the label applied in the immunoassay sensing process should have numerous characteristics: chemical stability, low cost, negligible effect on the binding performance, feasibility, safety, and applicable instrumentation. It is important to say that immunosensing assays are commonly used for high sensitivity detecting of different kinds of viruses, for example, SARS CoV-2 [131-135], HIV [136-138], HBV [139], and HCV $[140,141]$.
The incident of the novel coronavirus infection (SARSCoV-2) immediately spread everywhere throughout the world, and due to severe contagiosum of this virus, it is critical to develop point-of-care (POC) diagnosis assays for monitoring and management of disease in the afflicted area, even though the infection (SARS-Cov-2) nucleic acid RTPCR test has become the standard strategy for recognition of SARS-CoV-2 disease. Anyway, as a result of these real-time PCR test packs, confinements, and high false-negative rates, there is a pressing need for an exact and rapid diagnostic assay. POCT include tests that analyze patient specimens in place, outside the clinical laboratory. POCTs are often performed by clinical staff without laboratory training or by patients themselves for self-monitoring for obtaining a quick result close to the patient's bedside. POCT assay based on lateral flow immunoassays (LFIA) is developed for COVID19 detection and some of the marketed products. Recently, a rapid and portable detection device based on lateral flow immunoassay has been introduced by Liu et al., which can identify SARS-CoV-2 IgM and IgG antibodies at the same time in the blood of infected patients in 15 min which can distinguish patients at various disease stages. Lateral flow tests [142], otherwise called lateral flow immunochromatographic assessments, are straightforward and simple paperbased devices which are gadget-planned to recognize the presence of an objective analyte in a fluid sample without requiring any specific and exorbitant hardware. Lateral flow assays depend on a progression of capillary beds, for example, bits of permeable paper [143], microstructured polymer [144, 145], or sintered polymer. Each of these pads has the ability to spontaneously migrate liquid samples (e.g., saliva, blood, urine). It has been shown that IgM and IgG antibodies can be detected in the blood of patients 3 to 6 days and 8 days after the SARS-CoV infection, respectively. Therefore, recognition of both IgM and IgG antibodies could offer evidence on virus infection time, which could be very helpful for diagnosis and providing effective and timely remedies for COVID-19 patients. The sensitivity, reliability, and specificity of the prepared kit were approved by blood samples provided by 397 qRT-PCR-confirmed COVID-19 patients and 128 negative patients from eight clinical centers. The general testing sensitivity was $88.66 \%$ and specificity was $90.63 \%$. Likewise, estimating clinical determination results acquired from various sorts of venous and fingerstick blood tests have been performed. The IgM-IgG combined assay has better utility and sensitivity in comparison with a 
single IgM or IgG assay. It very well may be utilized for the rapid screening of SARS-CoV-2 carriers, asymptomatic or symptomatic peoples, and is very useful for hospitals, clinics, and laboratories. Furthermore, it can be employed for the detection of infected peoples in businesses, universities, airports, train stations, etc. Figure 12 demonstrates the schematic illustration of rapid SARS-CoV-2 IgM-IgG combined antibody test [133].

Electrochemical immunosensors have been explored as an appealing choice due to their excellent sensitivity, relatively low cost, ease of use, short response time, and the possibility of miniaturization. Recently, a novel indirect competitive assay based on electrochemical immunosensor has been introduced for the detection of the MERS-CoV virus. The biosensor is based on the indirect competition between the immobilized MERS-CoV protein and free virus in the sample for the fixed amount of added antibodies to the sample (Fig. 13), which was performed on a carbon electrodes (DEP) array changed by the gold NPs. This immunosensor is developed on DPE array to enable the simultaneous and rapid detection of various types of $\mathrm{CoV}$ virus. Recombined spike protein $\mathrm{S} 1$ has been utilized as a biomarker for MERS CoV. Square wave voltammetry (SWV) has been used to record the electrochemical measurements with the help of ferricyanide/ferrocyanide as a probe. A good linear response from 0.01 to $10,000 \mathrm{ng} \mathrm{mL}^{-1}$ and 0.001 to $100 \mathrm{ng} \mathrm{mL}^{-1}$ has been monitored for $\mathrm{HCoV}$ and MERS-CoV, respectively. The assay time has been performed in $20 \mathrm{~min}$, and the detection limit was as low as 1.0 and $0.4 \mathrm{pg} \mathrm{mL}^{-1}$ for MERS-CoV and $\mathrm{HCoV}$, respectively. The prepared disposable DEP array electrode has been promising to lower the cost and enable the multiplex-bead assays for the detection of $\mathrm{HCoV}$ and MERS-CoV simultaneously [146].

A piezoelectric (PZ) sensor is an efficient device that uses the piezoelectric effect to measure variations in pressure, temperature, acceleration, force, or strain and convert these changes into an electrical signal. A piezoelectric immunosensor has also been presented to detect SARS-CoV in the sputum in the gas phase. For the preparation of this biosensor, PZ polyclonal antibodies against SARS-CoV were attached to the surface of PZ crystal in an oriented state via protein A. On the other hand, the antigen sample has been atomized into the aerosol with the help of an ultrasonicator so that the antibodies existed on the surface of PZ crystal were capable of specifically adsorbing the SARS-CoV antigen and leading to a change on the crystal mass which could

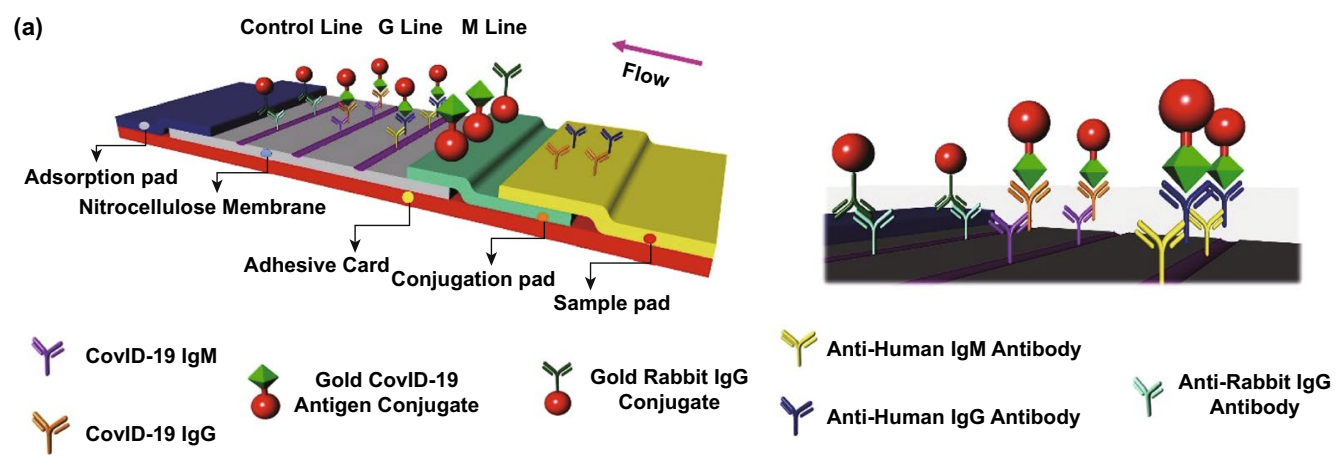

(b)

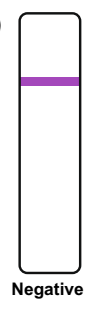

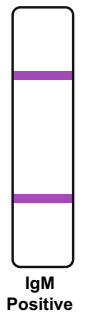
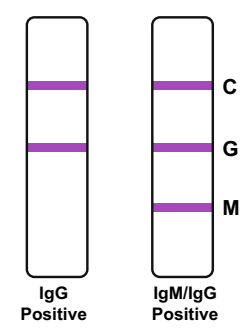

(c)

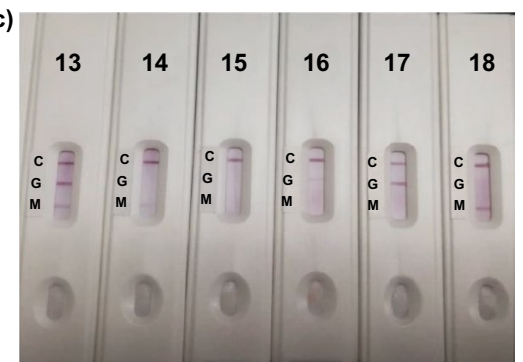

Fig. 12 Schematic explanation of quick SARS-CoV-2 IgM-IgG combined antibody test. a Schematic of the recognition device. b An explanation of various experimental consequences. $\mathbf{c}$ Relates to the control line, G means IgG line, M pertinent to IgM line. Illustrative photograph for various patient blood experimental consequences. \#13 shows both IgG and IgM positive, \#14 shows IgM weak positive, \#15 illustrate both IgG and IgM negative, \#16) IgG weak positive, \#17) IgG positive, \#18) IgM positive. (Redrawn from Ref. [133]) 


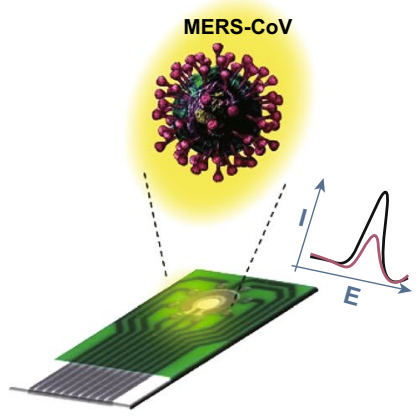

(a)

(b)

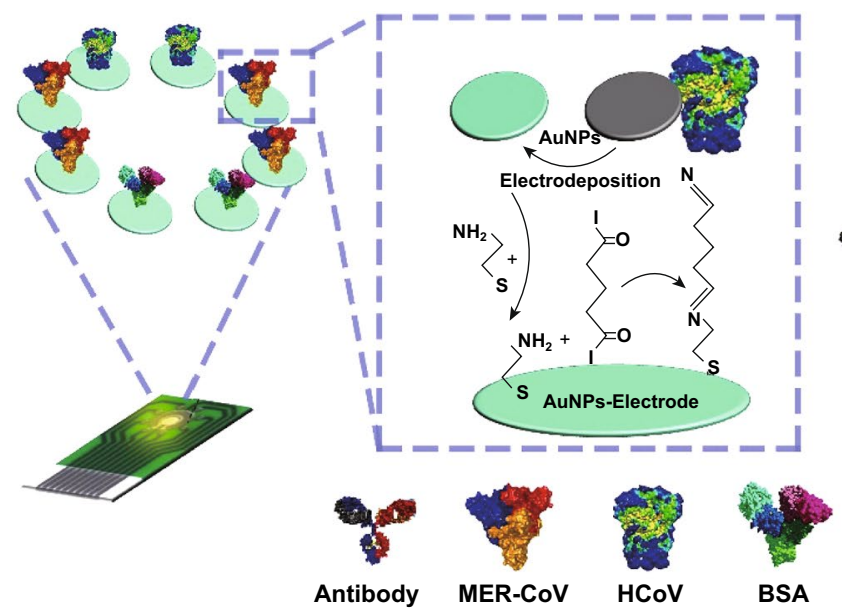

(c)

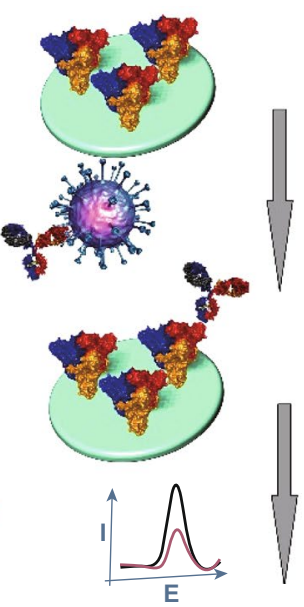

Fig. 13 Scheme demonstrating the MERS-CoV immunosensor preparation and also the recognition procedure. The biosensor comprises a competitive immunoassay carried out on DEP array electrodes nanostructured with gold nanoparticles to allow the multiplexed recognition of various CoV. a Immunosensor array chip for coronavirus. b Stages of immunosensor construction. $\mathbf{c}$ Recognition procedure of competitive immunosensor for the virus. Redrawn from Ref. [146]

provide a change in the frequency. In optimum situations, changes in frequency depended on the concentration of antigen to an extent from 0.6 to $4 \mu \mathrm{g} \mathrm{mL}^{-1}$ in a linear manner. The device contains short analyzing time (less than $2 \mathrm{~min}$ ), feasibility, specificity, simplicity, stability (immunosensor has been stable for more than 2 months when stored at the temperature of 4- $6{ }^{\circ} \mathrm{C}$ over silica gel blue), and great duplicability (it was capable of being reused 100 times without any sensible changes in the activity [147]).

\subsection{Apta Assays}

Aptamers, which are categorized as a sensing method, are short-chain oligonucleotides (either RNA or single-stranded DNA) that were concurrently introduced by three groups of scientists: Robertson and Joyce, Tuerk and Gold, and Ellington and Szostak [148]. One of the main properties that renders apta-assays as unique is their extraordinary affinity, which is an outcome of their flexibility and the ability to fold upon binding to a target. Their extraordinary advantages are small size, high specificity for target molecules, applicability both in vitro and in vivo, biocompatibility, low costs of production, high molecular stability, and low detection limits (as low as $\mathrm{zmol} \mathrm{L}^{-1}$ ). Aptamers, as biological ligands, strongly and selectively bind to the target analyte. Another interesting feature of aptamers is that they effectively preserve their properties in various experimental conditions [149, 150]. Aptasensing bio-assays have various recognition mechanisms and can bind to a wide range of regulatory proteins $[138,151]$, enzymes $[152,153]$, monoand polyclonal antibodies [154], amino acids [155], growth factors [156], toxins [157], low molecular weight vitamins [158], cancer biomarkers [159-161], and even some metal ions [162]. Large quantities of aptamers can be biochemically synthesized most frequently through the systematic evolution of ligands by exponential enrichment (SELEX). Other synthesizing methods include non-equilibrium capillary electrophoresis of equilibrium mixture (NECEEM) [163] and high-throughput aptamer identification screen (HAPIscreen). Aptamers, despite their advantages and versatility, also have disadvantages that may limit their usefulness; these limitations are sensitivity to nuclease degradation, not binding to some targets that lack functional groups, and stronger (and sensitive to enzymatic digestion) bonds with antibodies than target analytes. In the following section, main aptasensing assays for effective determination of human coronaviruses will be discussed.

SELEX referred to as in vitro evolution or in vitro selection is a combinatorial chemistry method in molecular biology for the screening of single-stranded DNA or RNA that specifically binds to a target ligand or ligands with high affinity $[164,165]$. Because of the benefits of better stability, simple modification, and easy preparation, aptamers were utilized to fabricate biosensors for detecting infectious 
microorganisms. The present research work provides the most recent improvements in SELEX to screen aptamers in infectious microorganisms and represents several described aptamers in infective microorganisms (bacteria, viruses, protozoa) and examines biosensors based on aptamer to detect infectious microorganisms. Consequently, the novel movements in biosensors based on aptamers for detecting infectious microorganisms can be debated [166].

SARS-CoV is the etiology-pertained factor for the recently appeared SARS disease. The nucleocapsid protein $(\mathrm{N})$ of SARS-CoV is the most plentiful structure-pertained protein and has the function of a recognition marker for detecting the virus accurately and sensitively. An RNA aptamer with high affinity is selected, which could bind to $\mathrm{N}$ protein with a dissociation constant equal to $1.65 \mathrm{nM}$. Results demonstrated that the selected aptamer can be identified in the $\mathrm{C}$ domain of $\mathrm{N}$ protein with high specificity in a selective manner. Isolated aptamers can act as a capturing agent for the $\mathrm{N}$ protein molecules for the fabrication of an aptamer-based chemiluminescence immunosorbent assay and in a nanoarray aptamer. The prepared aptamer-antibody hybrid immunoassays can detect the low level of $\mathrm{N}$ protein $\left(2 \mathrm{pg} \mathrm{mL}^{-1}\right)$ with high sensitivity and selectivity. Such aptamer-antibody combined immunoassays can be practically used for the rapid detection of the $\mathrm{N}$ protein of SARS-CoV with high sensitivity [167].

Among different SARS-CoV structure-pertained proteins, the protein of nucleocapsid was considered as a better recognition biomarker. An aptamer of ssDNA was isolated against the $\mathrm{N}$ protein from a DNA library containing $45 \mathrm{nt}$ with random sequences. The analysis of ELISA shows that this aptamer can identify SARS-CoV nucleocapsid protein with a high binding affinity (with a Kd of $4.93 \pm 0.30 \mathrm{nM}$ ). Furthermore, the result of western blot analysis confirmed that such an aptamer of ssDNA could effectively detect the SARS-CoV N protein when compared to the nucleocapsid antibodies. Thus, the isolated aptamer of ssDNA can be useful as an alternative detection probe for the rapid and sensitive diagnosis of SARS [168].

The $\mathrm{N}$ protein is one of the most important antigens used for the early detection of SARS-CoV infection. An optical biosensor based on quantum dots (QDs)-conjugated RNA aptamer platform with high sensitivity and specificity was designed for rapid diagnosis of SARS-CoV N protein on a chip system. QDs are colloidal nanomaterials belonging to semiconductor materials, which have attracted much attention in the fields of nanomedicine, especially in imaging systems due to their unique optical properties compared with traditional fluorophores in terms of being longer fluorescence lifetime, high stability, and tunable emission spectra $[124,169]$. For this purpose, SARS-CoV N protein immobilized on the surface of a glass chip could be effectively hybridized by QDs-conjugated RNA aptamer for the creation of fluorescence signals. The intensity of fluorescence signals is related to the concentration of SARS N protein. This miniaturization device based on optical QDs-RNA aptamer chip can detect SARS-CoV N protein at the concentrations of as low as $0.1 \mathrm{pg} \mathrm{mL}^{-1}$. The suggested graphical SARS-CoV N protein method enjoys high sensitivity, accuracy, simplicity, and easy operation [170]. Table 2 presents a comparison between different methods for the detection of coronaviruses.

\section{Summary and Future Outlooks}

In this paper, we describe some important detection methods of various types of coronavirus, including clinical and sensor-based methods. Currently, the lack of any rapid, available, and reliable POC detection method gives rise to the progression of COVID-19 as a horrible global problem. Most of the countries around the world had underestimated the novel coronavirus infection and ignored any plan to prevent the spread. Since other clinical detection methods such as ELISA or RT-PCR were feasible for previous epidemic viral infections, the SARS-CoV-2 was also accounted for the mild respiratory viral infection and assessed by the earlier methods. However, this new coronavirus has less mortality rate than SARS or MERS-CoV; SARS-CoV-2 is transmitted more quickly from human to human. Moreover, this virus can modify its genome via a mechanism called template switching that gives it the ability to change the virus RNA sequence and even in the amino acidic stage [171].

Immunoassay-based methods such as ELISA are among common methods to detect a variety of virus-derived antigens or their corresponding antibodies for diagnostic purposes or determining the efficiency of vaccination. The sensitivity of SARS-CoV N-based IgG ELISA is significantly higher than that of SARS-CoV S-based IgG ELISA, but the sensitivity of SARS-CoV-2 IgG/IgM still remains to be studied. Hampered results are among serious challenges and may occur due to a range of problems (false negativity, noise, unspecific reactions). Additionally, the 
Table 2 Summary of presented methods for detection of coronaviruses

\begin{tabular}{|c|c|c|c|c|c|c|c|}
\hline Technique & Sensitivity & Specificity & LOD & Cost & Detecting time & Advantages & Disadvantages \\
\hline CT scan & Very high & Low & High & 100-1000 USD & $30 \mathrm{~min}$ & $\begin{array}{l}\text { *Short executive } \\
\text { time } \\
\text { *High-resolution } \\
\text { image } \\
\text { *Providing unique } \\
\text { medical informa- } \\
\text { tion }\end{array}$ & $\begin{array}{l}\text { *Exposure to the } \\
\text { radiation } \\
\text { *Expensive } \\
\text { * No information } \\
\text { about the cause of } \\
\text { disease }\end{array}$ \\
\hline Real-time PCR & $\begin{array}{l}10 \text { copies of } \\
\text { nucleic acid per } \\
\mu \mathrm{L}\end{array}$ & Moderate & Low & 40-60 USD & $4-6 h$ & $\begin{array}{l}\text { *Popularity and } \\
\text { credibility among } \\
\text { scientists } \\
\text { *Determining the } \\
\text { exact infection } \\
\text { stage } \\
\text { *Detecting low } \\
\text { level of RNA/ } \\
\text { DNA }\end{array}$ & $\begin{array}{l}\text { * Not suitable for } \\
\text { screening after } \\
\text { clearance } \\
\text { *Variety in the repli- } \\
\text { cation site of virus } \\
\text { and sampling site } \\
\text { *Showing only acute } \\
\text { infection }\end{array}$ \\
\hline LAMP & $\begin{array}{l}\text { 10-100-fold higher } \\
\text { than RT-PCR }\end{array}$ & Moderate & Low & Low & $<1 \mathrm{~h}$ & $\begin{array}{l}\text { *Low-cost equip- } \\
\text { ment } \\
\text { *No need for ther- } \\
\text { mal alternations } \\
\text { *Possibility to } \\
\text { be reported with } \\
\text { naked eyes }\end{array}$ & $\begin{array}{l}\text { *Can be inhib- } \\
\text { ited with some } \\
\text { constituents within } \\
\text { samples } \\
\text { *Low versatility } \\
\text { *Possibility of } \\
\text { primer-primer } \\
\text { interactions }\end{array}$ \\
\hline ELISA & $0.01-0.1 \mathrm{ng}$ & High & Moderate & 20-40 USD & $1-2 \mathrm{~h}$ & $\begin{array}{l}\text { *Detecting anti- } \\
\text { gens at nano- or } \\
\text { picogram level. } \\
\text { *High detection } \\
\text { throughput } \\
\text { *Ease of perform- } \\
\text { ing } \\
\text { *Quantitative } \\
\text { measurement } \\
\text { *Applicability } \\
\text { with a variety of } \\
\text { samples }\end{array}$ & $\begin{array}{l}* \text { Temporary reading } \\
\text { time } \\
\text { *Low reported infor- } \\
\text { mation }\end{array}$ \\
\hline $\begin{array}{l}\text { Sensing/Biosens- } \\
\text { ing assays }\end{array}$ & $\begin{array}{l}1 \text { pg-200 ng per } \\
\mathrm{mL}\end{array}$ & High & Very low & 5-10 USD & $\begin{array}{l}\text { Less than } \\
10 \mathrm{~min}\end{array}$ & $\begin{array}{l}\text { *Short executive } \\
\text { time } \\
\text { *Detecting targets } \\
\text { in very low } \\
\text { amount } \\
\text { *Cheap } \\
\text { *Longer response } \\
\text { time and high } \\
\text { stability } \\
\text { * No need for } \\
\text { biocatalysts }\end{array}$ & $\begin{array}{l}\text { *Need for sample } \\
\text { preparation } \\
\text { *Tedious process } \\
\text { *Affected by tem- } \\
\text { perature or pH }\end{array}$ \\
\hline
\end{tabular}

method requires a relatively long time to be completed. In general, ELISA kits are costly and need skilled personnel to conduct the procedure, use the equipment, and interpret and report the results. These challenges warrant for developing other methods to overcome these issues. Immune-PCR (IPCR) is a method that uses both specificity of antibody-antigen and sensitivity of PCR. ELISA sensitivity is not enough to identify viral protein of low abundance, while it can detect any protein and PCR cannot be used directly for viral protein detection since it does not utilize antibodies. IPCR reproducibly increases sensitivity (10- to 1000-fold) for detection of pico-femtogram 
analyte from serum/urine, while provides multiplexing option because of ELISA and PCR combination (through an antibody-oligonucleotide conjugate) [172].

The delicate detection and enumeration of viruses are done by an excellent tool called real-time RT-PCR, where the improved product created through each cycle is quantified either by using SYBR Green or by numerous fluorescent probe chemistries to diagnose SARS-CoV-2; although RTqPCR is specific, its false-negative rate cannot be overlooked because of the severe aftereffects of missed diagnosis. At present, next-generation sequencing (NGS) is progressively employed to understand the molecular epidemiology, transmission, and characterization of viruses. By performing a single test, large deposits of genes present in clinical samples can be identified rather than employing gene-by-gene analysis. In June 2020, FDA granted an EUA to Illumina, Inc. for the first COVID-19 diagnostic test utilizing NGS technology. It is the first authorization for NGS to use in diagnostics. In this test, 98-bp DNA fragment of SARC-COV-2 genome was used. Its limits are 1000 copy of viral genome per milliliter of sample, and it showed $97 \%$ specificity and $98 \%$ sensitivity. By using NGS test, not only virus can be detected but also it will provide sequence information of SARS-COV-2, which can be used to understand more about mutation and route of transmission over time [173].

Among the other approaches investigated between molecular approaches and PCR or recognition of viral diseases, LAMP-based methods are of great importance due to their numerous benefits. The most spectacular advantages of LAMP assays are the use of less equipment, availability, cheapness, quick detection, and also technically sound test. Efficient primer design is the main precondition of LAMP utilizing in a fertile way. As an accurate, fast, and cheap method for diagnosis, LAMP is employed to selectively amplify the target nucleic acid in isothermal conditions. There is no need for complex instruments; a water bath is enough and the completion time is about $1 \mathrm{~h}$ through LAMP method. In this method, the results are directly visible when SYBR Green or hydroxynaphthol blue (HNB) or calcein dyes are added. When a ladderlike outline is observed, we can also use gel electrophoresis. The outcome of improvements in molecular biology and biotechnology field is that the primer designing becomes a little tranquil, but there is a need for more investigations in the future for false positivity of the LAMP reaction.

As reactions can be done and outcomes can be read without opening reaction tubes, it demonstrates the great potential of LAMP in disease recognition. CT scan and RT-qPCR are notable for the diagnosis of SARS-CoV-2; most of the clinicians proposed that $\mathrm{CT}$ scans should be one necessary auxiliary diagnostic method; Table 2 summarizes the comparison between different methods for detection of coronaviruses. Because it is more sensitive than RT-qPCR for cases with a high clinical suspicion of the infection with negative RT-qPCR screening, a combination of repeated RT-qPCR tests and chest CT scan may be helpful.

To overcome these challenges, we need to design a novel detection method solving the problems of old clinical methods as well as the ability of conformation with the features of this new coronavirus. Immunosensor-based techniques are designed and used solely to eliminate the disadvantages of old clinical methods and are, therefore, of great importance. They have several benefits, including rapid detection, low cost, availability, and ability to detect the low concentrations of the desired material. These techniques are also appropriate to detect several parts of coronavirus particles, which can solve the problem of coronavirus mutations and false-negative results. On the other hand, in comparison with sensing, biosensing, apta-sensing, and immunosensing assays, LFAs (lateral flow assays) are more important and attractive POC devices for widespread uses. The important benefits they can provide are simple test processes, low sample volume requirements, rapid analysis, no necessity for expert staff, low cost of performance, user-friendly, and also cost-effective characteristics. Given the needs of communities for detecting the infectious agents at the early stage to inhibit the wide scale of prevalence, future studies must be aimed to find a proper method rather than usual clinical methods, as the rapid POC test for finding pathogenic viral infections and in particular coronavirus earlier than ever. The health care provider systems of all countries should be equipped with a distinguished platform having the ability to design new methods to detect likely future mutated viruses to prevent further epidemics or pandemics.

Development of point-of-care testing (POCT) of IgM/IgG (immune identification technology), biosensing assay and nanobiosensors for precise, suitable, and rapid detection of $\mathrm{N}$ protein biomarker of SARS-CoV, immunosensor array chip, microarray-based detection, LFA detection methods with higher sensitivity, all are ongoing endeavor. LFA with multiple functions, as well as biosensors and nanobiosensors tracers and accompanied detecting devices, may help to 
upgrade the efficacy of detection approaches. These biosensors are hoped to be utilized for detecting the SARS-COV2 virus as the accurate commercial biosensors that are now available in the market for diagnosis of HIV and influenza.

Some high-sensitivity biosensors are moving forward toward clinical trials. As example, one can mention chromatographic immunoassays for detecting influenza viruses (types A and B). These tests provide a colorimetric and qualitative identification of the virus in respiratory secretions. Other commercial biosensors for influenza $\mathrm{A}$ and $\mathrm{B}$ virus detection are as follows: Quidel, USA; Alere, USA; Directigen EZ Flu A+B, USA; SAS FluAlert A\&B, USA; Coris BioConcept, Belgium, Thermo, USA; and OraSure Technologies, Inc., USA. There are also examples of these biosensors for HIV that are now available on the market: Runbio Biotech Co. Ltd., China; Alere, USA; Standard Diagnostics, Inc., Korea; and JAL Innovation, Taiwan [68, 174].

In the upcoming years, we should move toward producing cheap multifunctional biosensors that can support all the necessary detecting phases in a simplified manner. Also, we should solve the problem of complex storage requirements of the reagents, for example, by keeping all of them on a chip. The output of biosensors can be enhanced by applying biosensors with multiplexing features. Furthermore, the outputs should be presented quantitatively to obtain more accurate and more accessible (e.g., smartphone applications) results. Developing smaller size platforms is one approach toward applying such phone apps, as well as utilizing LFA, biosensors, and nanobiosensors detection techniques. Therefore, for developing portable detection systems which give the possibility for remote diagnostics, the size of detection systems should become as minimized as possible. Nevertheless, these miniaturized systems must be able to deliver all the functions of an optimal diagnostic test, such as simplicity, affordability, user-friendly, and the abilities to store, import, and export results.

Briefly, developing point-of-care biosensors and nanosensors with these features can provide the opportunity to rapidly screen the SARS-COV2 virus in populations and confine the virus spread.

Acknowledgements The authors are grateful for financial support from the Immunology Research Center, Tabriz University of Medical Sciences. The authors are also thankful for the support rendered by the University of Tabriz. The authors hereby express their thanks for the support rendered by Nanjing Forestry University [Grant Nos. 163020139, 164020818, 163020217 and 16302023], and National Natural Science Foundation of China (5201101466). The authors also wish to express their special thanks to Professor Alireza Khataee, Seyed Mehdi Tabatabaei (MD, FICS, Assistant professor, Glaucoma Service, Farabi Eye Hospital, Tehran University of Medical Sciences), Hamed Rezaei (MD, Department of Urology, Tehran University of Medical Sciences (TUMS)), Dr. Shahriar Dadkhah Tehrani and Professor Fatih Sen for their contributions to the current work.

Open Access This article is licensed under a Creative Commons Attribution 4.0 International License, which permits use, sharing, adaptation, distribution and reproduction in any medium or format, as long as you give appropriate credit to the original author(s) and the source, provide a link to the Creative Commons licence, and indicate if changes were made. The images or other third party material in this article are included in the article's Creative Commons licence, unless indicated otherwise in a credit line to the material. If material is not included in the article's Creative Commons licence and your intended use is not permitted by statutory regulation or exceeds the permitted use, you will need to obtain permission directly from the copyright holder. To view a copy of this licence, visit http://creativecommons.org/licenses/by/4.0/.

\section{References}

1. C. Drosten, S. Gunther, W. Preiser, S. van der Werf, H.R. Brodt et al., Identification of a novel coronavirus in patients with severe acute respiratory syndrome. N. Engl. J. Med. 348(20), 1967-1976 (2003). https://doi.org/10.1056/NEJMo a030747

2. M.R. Keogh-Brown, R.D. Smith, The economic impact of SARS: How does the reality match the predictions? Health Policy 88(1), 110-120 (2008). https://doi.org/10.1016/j.healt hpol.2008.03.003

3. R.J. de Groot, S.C. Baker, R.S. Baric, C.S. Brown, C. Drosten et al., Commentary: middle east respiratory syndrome coronavirus (MERS-CoV): announcement of the coronavirus study group. J. Virol. 87(14), 7790-7792 (2013). https://doi. org/10.1128/JVI.01244-13

4. A.M. Zaki, S. van Boheemen, T.M. Bestebroer, A.D. Osterhaus, R.A. Fouchier, Isolation of a novel coronavirus from a man with pneumonia in Saudi Arabia. N. Engl. J. Med. 367(19), 1814-1820 (2012). https://doi.org/10.1056/NEJMo a1211721

5. A.C.P. Wong, X. Li, S.K.P. Lau, P.C.Y. Woo, Global epidemiology of bat coronaviruses. Viruses 11(2), 174 (2019). https ://doi.org/10.3390/v11020174

6. E. de Wit, N. van Doremalen, D. Falzarano, V.J. Munster, SARS and MERS: recent insights into emerging coronaviruses. Nat. Rev. Microbiol. 14(8), 523 (2016). https://doi. org/10.1038/nrmicro.2016.81

7. Coronaviridae Study Group of the International Committee on Taxonomy of Viruses. The species severe acute respiratory syndrome-related coronavirus: classifying 2019-nCoV 
and naming it SARS-CoV-2. Nat. Microbiol. 5(4), 536-544 (2020). https://doi.org/10.1038/s41564-020-0695-z

8. W.H. Organization, Coronavirus disease (covid-2019) situation reports. https://www.who.int/emergencies/diseases/novel -coronavirus-2019/situation-reports

9. J.F. Chan, S. Yuan, K.H. Kok, K.K. To, H. Chu et al., A familial cluster of pneumonia associated with the 2019 novel coronavirus indicating person-to-person transmission: a study of a family cluster. Lancet 395(10223), 514-523 (2020). https ://doi.org/10.1016/S0140-6736(20)30154-9

10. (ICTV) ICoToV. Virus taxonomy. (2019, January)

11. A.R. Fehr, S. Perlman (2015) in Coronaviruses: An overview of their replication and pathogenesis. ed. by (Springer), pp. 1-23. https://doi.org/10.1007/978-1-4939-2438-7_1

12. D.R. Beniac, A. Andonov, E. Grudeski, T.F. Booth, Architecture of the SARS coronavirus prefusion spike. Nat. Struct. Mol. Biol. 13(8), 751-752 (2006). https://doi.org/10.1038/ nsmb1123

13. A.C. Walls, Y.J. Park, M.A. Tortorici, A. Wall, A.T. McGuire, D. Veesler, Structure, function, and antigenicity of the SARS-CoV-2 spike glycoprotein. Cell 181(2), 281-292 (2020). https://doi.org/10.1016/j.cell.2020.02.058

14. J. Ziebuhr, E.J. Snijder, A.E. Gorbalenya, Virus-encoded proteinases and proteolytic processing in the nidovirales. J. Gen. Virol. 81(Pt 4), 853-879 (2000). https://doi. org/10.1099/0022-1317-81-4-853

15. J. Tooze, S. Tooze, G. Warren, Replication of coronavirus MHV-a59 in sac- cells: determination of the first site of budding of progeny virions. Eur. J. Cell Biol. 33(2), 281-293 (1984)

16. C.A. de Haan, P.J. Rottier, Molecular interactions in the assembly of coronaviruses. Adv. Virus Res. 64, 165-230 (2005). https://doi.org/10.1016/S0065-3527(05)64006-7

17. M. Catanzaro, F. Fagiani, M. Racchi, E. Corsini, S. Govoni, C. Lanni, Immune response in covid-19: addressing a pharmacological challenge by targeting pathways triggered by SARS-CoV-2. Signal Transduct. Target Ther. 5(1), 84 (2020). https://doi.org/10.1038/s41392-020-0191-1

18. S. Khan, J. Liu, M. Xue, Transmission of SARS-CoV-2, required developments in research and associated public health concerns. Front. Med. 7, 310 (2020). https://doi. org/10.3389/fmed.2020.00310

19. V. Khot, M. Strous, A.K. Hawley, Computational approaches in viral ecology. Comput. Struct. Biotechnol. J. 18, 1605-1612 (2020). https://doi.org/10.1016/j. csbj.2020.06.019

20. A.V. Ivanov, I.V. Safenkova, A.V. Zherdev, B.B. Dzantiev, Nucleic acid lateral flow assay with recombinase polymerase amplification: solutions for highly sensitive detection of RNA virus. Talanta 210, 120616 (2020). https://doi.org/10.1016/j. talanta.2019.120616

21. R. Wang, R. Yu, B. Chen, F. Si, J. Wang et al., Identification of host cell proteins that interact with the $\mathrm{M}$ protein of porcine epidemic diarrhea virus. Vet. Microbiol. (2020). https:// doi.org/10.1016/j.vetmic.2020.108729
22. S. Long, B. Berkemeier, Maximizing viral detection with SIV droplet digital PCR (ddPCR) assays. PLoS ONE 15(5), e0233085 (2020). https://doi.org/10.1371/journal.pone.02330 85

23. A. Tahamtan, A. Ardebili, Real-time RT-PCR in COVID19 detection: issues affecting the results. Expert Rev. Mol. Diagn. 20, 453-454 (2020). https://doi.org/10.1080/14737 159.2020.1757437

24. N. Merindol, G. Pépin, C. Marchand, M. Rheault, C. Peterson et al., SARS-CoV-2 detection by direct rRT-PCR without RNA extraction. J. Clin. Virol. 128, 104423 (2020). https:// doi.org/10.1016/j.jcv.2020.104423

25. F. Yu, L. Yan, N. Wang, S. Yang, L. Wang et al., Quantitative detection and viral load analysis of SARS-CoV-2 in infected patients. Clin. Infect. Dis. 71(15), 793-798 (2020). https:// doi.org/10.1093/cid/ciaa345

26. R. Liu, H. Han, F. Liu, Z. Lv, K. Wu et al., Positive rate of RT-PCR detection of SARS-CoV-2 infection in 4880 cases from one hospital in Wuhan, China, from Jan to Feb 2020. Clin. Chim. Acta 505, 172-175 (2020). https://doi. org/10.1016/j.cca.2020.03.009

27. I.-N. Lu, C.P. Muller, F.Q. He, Applying next-generation sequencing to unravel the mutational landscape in viral quasispecies: a mini-review. Virus Res. (2020). https://doi. org/10.1016/j.virusres.2020.197963

28. M.H. Cleveland, B. Anekella, M. Brewer, P.J. Chin, H. Couch et al., Report of the 2019 NIST-FDA workshop on standards for next generation sequencing detection of viral adventitious agents in biologics and biomanufacturing. Biologicals 64, 76-82 (2020). https://doi.org/10.1016/j.biological s. 2020.02 .003

29. N.T.T. Hong, N.T. Anh, N.T.H. Mai, H.D.T. Nghia, L.N.T. Nhu et al., Performance of metagenomic next-generation sequencing for the diagnosis of viral meningoencephalitis in a resource-limited setting. Open Forum Infect. Dis. 7(3), ofaa046 (2020). https://doi.org/10.1093/ofid/ofaa046

30. E.R. Lee, N. Parkin, C. Jennings, C.J. Brumme, E. Enns et al., Performance comparison of next generation sequencing analysis pipelines for HIV-1 drug resistance testing. Sci. Rep. 10(1), 1634 (2020). https://doi.org/10.1038/s41598-02058544-z

31. L.A.E. Van Poelvoorde, X. Saelens, I. Thomas, N.H. Roosens, Next-generation sequencing: an eye-opener for the surveillance of antiviral resistance in influenza. Trends Biotechnol. 38(4), 360-367 (2020). https://doi.org/10.1016/j.tibte ch.2019.09.009

32. G. Seo, G. Lee, M.J. Kim, S.-H. Baek, M. Choi et al., Rapid detection of COVID-19 causative virus (SARS-CoV-2) in human nasopharyngeal SWAB specimens using field-effect transistor-based biosensor. ACS Nano 14(4), 5135-5142 (2020). https://doi.org/10.1021/acsnano.0c02823

33. L. Farzin, M. Shamsipur, L. Samandari, S. Sheibani, Hiv biosensors for early diagnosis of infection: the intertwine of nanotechnology with sensing strategies. Talanta 206, 120201 (2020). https://doi.org/10.1016/j.talanta.2019.120201 
34. M.Z.H. Khan, M.R. Hasan, S.I. Hossain, M.S. Ahommed, M. Daizy, Ultrasensitive detection of pathogenic viruses with electrochemical biosensor: state of the art. Biosens. Bioelectron. 166, 112431 (2020). https://doi.org/10.1016/j. bios.2020.112431

35. E. Ghazizadeh, S.E. Moosavifard, N. Daneshmand, S.K. Kaverlavani, Impediometric electrochemical sensor based on the inspiration of carnation italian ringspot virus structure to detect an attommolar of miR. Sci. Rep. 10(1), 9645 (2020). https://doi.org/10.1038/s41598-020-66393-Z

36. E.P. Simão, D.B. Silva, M.T. Cordeiro, L.H. Gil, C.A. Andrade, M.D. Oliveira, Nanostructured impedimetric lectin-based biosensor for arboviruses detection. Talanta $\mathbf{2 0 8}$, 120338 (2020). https://doi.org/10.1016/j.talanta.2019.120338

37. E.I. Tzianni, J. Hrbac, D.K. Christodoulou, M.I. Prodromidis, A portable medical diagnostic device utilizing free-standing responsive polymer film-based biosensors and low-cost transducer for point-of-care applications. Sens. Actuator B Chem. 304, 127356 (2020). https://doi.org/10.1016/j. snb.2019.127356

38. J. Mohanraj, D. Durgalakshmi, R.A. Rakkesh, S. Balakumar, S. Rajendran, H. Karimi-Maleh, Facile synthesis of paper based graphene electrodes for point of care devices: a double stranded DNA (dsDNA) biosensor. J. Colloid Interface Sci. 566, 463-472 (2020). https://doi.org/10.1016/j. jcis.2020.01.089

39. I.M. Mackay, K.E. Arden, A. Nitsche, Real-time PCR in virology. Nucleic Acids Res. 30(6), 1292-1305 (2002). https ://doi.org/10.1093/nar/30.6.1292

40. U.E. Gibson, C.A. Heid, P.M. Williams, A novel method for real time quantitative RT-PCR. Genome Res. 6(10), 9951001 (1996). https://doi.org/10.1101/gr.6.10.995

41. V.M. Corman, I. Eckerle, T. Bleicker, A. Zaki, O. Landt et al., Detection of a novel human coronavirus by real-time reverse-transcription polymerase chain reaction. Euro. Surveill. 17(39), 20285 (2012). https://doi.org/10.2807/ ese.17.39.20285-en

42. W.H. Organization PCR primers for sars developed by who network laboratories. (2003, 17 April)

43. W.H. Organization, Coronavirus disease (COVID-19) technical guidance: Laboratory testing for 2019-nCoV in humans. (Retrieved 2020, 18 March)

44. S.A. Bustin, T. Nolan, Pitfalls of quantitative real-time reverse-transcription polymerase chain reaction. J. Biomol. Tech. 15(3), 155-166 (2004)

45. D. Yang, J.L. Leibowitz, The structure and functions of coronavirus genomic $3^{\prime}$ and 5' ends. Virus Res. 206, 120-133 (2015). https://doi.org/10.1016/j.virusres.2015.02.025

46. T. Notomi, H. Okayama, H. Masubuchi, T. Yonekawa, K. Watanabe, N. Amino, T. Hase, Loop-mediated isothermal amplification of DNA. Nucleic Acids Res. 28(12), E63 (2000). https://doi.org/10.1093/nar/28.12.e63

47. Y. Mori, K. Nagamine, N. Tomita, T. Notomi, Detection of loop-mediated isothermal amplification reaction by turbidity derived from magnesium pyrophosphate formation. Biochem.
Biophys. Res. Commun. 289(1), 150-154 (2001). https://doi. org/10.1006/bbrc.2001.5921

48. Z.K. Njiru, A.S. Mikosza, T. Armstrong, J.C. Enyaru, J.M. Ndung'u, A.R. Thompson, Loop-mediated isothermal amplification (lamp) method for rapid detection of trypanosoma brucei rhodesiense. PLoS Negl. Trop. Dis. 2(1), e147 (2008). https://doi.org/10.1371/journal.pntd.0000147

49. L.L. Poon, C.S. Leung, K.H. Chan, J.H. Lee, K.Y. Yuen, Y. Guan, J.S. Peiris, Detection of human influenza a viruses by loop-mediated isothermal amplification. J. Clin. Microbiol. 43(1), 427-430 (2005). https://doi.org/10.1128/ JCM.43.1.427-430.2005

50. Y. Enomoto, T. Yoshikawa, M. Ihira, S. Akimoto, F. Miyake et al., Rapid diagnosis of herpes simplex virus infection by a loop-mediated isothermal amplification method. J. Clin. Microbiol. 43(2), 951-955 (2005). https://doi.org/10.1128/ JCM.43.2.951-955.2005

51. H.T.C. Thai, M.Q. Le, C.D. Vuong, M. Parida, H. Minekawa et al., Development and evaluation of a novel loop-mediated isothermal amplification method for rapid detection of severe acute respiratory syndrome coronavirus. J. Clin. Microbiol. 42(5), 1956-1961 (2004). https://doi.org/10.1128/ JCM.42.5.1956-1961.2004

52. G.-S. Park, K. Ku, S.-H. Beak, S.J. Kim, S.I. Kim, B.-T. Kim, J.-S. Maeng, Development of reverse transcription loop-mediated isothermal amplification assays targeting severe acute respiratory syndrome coronavirus 2 (SARSCoV-2). J. Mol. Diagn. 22(6), 729-735 (2020). https://doi. org/10.1016/j.jmoldx.2020.03.006

53. L.E. Lamb, S.N. Bartolone, E. Ward, M.B. Chancellor, Rapid detection of novel coronavirus (COVID19) by reverse transcription-loop-mediated isothermal amplification. https://doi.org/10.2139/ssrn.3539654

54. L. Yu, S. Wu, X. Hao, X. Li, X. Liu et al., Rapid colorimetric detection of COVID-19 coronavirus using a reverse transcriptional loop-mediated isothermal amplification (RT-LAMP) diagnostic platform: iLACO. medRxiv (2020). https://doi.org/10.1101/2020.02.20.20025874

55. G. Woźniakowski, E. Samorek-Salamonowicz, W. Kozdruń, Comparison of loop-mediated isothermal amplification and PCR for the detection and differentiation of marek's disease virus serotypes 1, 2, and 3. Avian Dis. 57(1), 539-543 (2013). https://doi.org/10.1637/10328 -082012-ResNote. 1

56. X. Wang, D.J. Seo, M.H. Lee, C. Choi, Comparison of conventional PCR, multiplex PCR, and loop-mediated isothermal amplification assays for rapid detection of arcobacter species. J. Clin. Microbiol. 52(2), 557-563 (2014). https:// doi.org/10.1128/JCM.02883-13

57. J.R. Crowther, Elisa: Theory and Practice (Springer, Berlin, 2001). https://doi.org/10.1385/0896032795

58. E. Engvall, P. Perlmann, Enzyme-linked immunosorbent assay, elisa. Iii. Quantitation of specific antibodies by enzyme-labeled anti-immunoglobulin in antigen-coated tubes. J. Immunol. 109(1), 129-135 (1972) 
59. S. Greer, G.J. Alexander, Viral serology and detection. Baillieres Clin. Gastroenterol. 9(4), 689-721 (1995). https ://doi.org/10.1016/0950-3528(95)90057-8

60. CfDCa. Prevention, CDC laboratory testing for middle east respiratory syndrome coronavirus (MERS-CoV). (2019, 29 August)

61. H.S. Wu, S.C. Chiu, T.C. Tseng, S.F. Lin, J.H. Lin et al., Serologic and molecular biologic methods for SARSassociated coronavirus infection, taiwan. Emerg. Infect. Dis. 10(2), 304-310 (2004). https://doi.org/10.3201/eid10 02.030731

62. J. Pang, M.X. Wang, I.Y.H. Ang, S.H.X. Tan, R.F. Lewis et al., Potential rapid diagnostics, vaccine and therapeutics for 2019 novel coronavirus (2019-nCoV): a systematic review. J. Clin. Med. 9(3), 623 (2020). https://doi.org/10.3390/jcm90 30623

63. J. Zhao, Q. Yuan, H. Wang, W. Liu, X. Liao et al., Antibody responses to SARS-CoV-2 in patients of novel coronavirus disease 2019. Clin. Infect. Dis. (2020). https://doi. org/10.1101/2020.03.02.20030189

64. K.K. To, O.T. Tsang, W.S. Leung, A.R. Tam, T.C. Wu et al., Temporal profiles of viral load in posterior oropharyngeal saliva samples and serum antibody responses during infection by SARS-CoV-2: an observational cohort study. Lancet Infect. Dis. 20(5), 565-574 (2020)

65. I. Diazyme Laboratories, Why do we need antibody tests for covid-19 and how to interpret test results. (2020)

66. M. Buheji, A.R. Buhiji, Designing intelligent system for stratification of covid-19 asymptomatic patients. Am. J. Med. Med. Sci. 10(4), 246-257 (2020). https://doi. org/10.5923/j.ajmms.20201004.17

67. T. Waritani, J. Chang, B. McKinney, K. Terato, An elisa protocol to improve the accuracy and reliability of serological antibody assays. MethodsX 4, 153-165 (2017). https:// doi.org/10.1016/j.mex.2017.03.002

68. S. Hassanpour, B. Baradaran, M. Hejazi, M. Hasanzadeh, A. Mokhtarzadeh, M. de la Guardia, Recent trends in rapid detection of influenza infections by bio and nanobiosensor. TrAC Trends Anal. Chem. 98, 201-215 (2018). https://doi. org/10.1016/j.trac.2017.11.012

69. Y. Lee, J.H. Ahn, Biomimetic tactile sensors based on nanomaterials. ACS Nano 14(2), 1220-1226 (2020). https://doi. org/10.1021/acsnano.0c00363

70. A. Szuplewska, D. Kulpinska, A. Dybko, M. Chudy, A.M. Jastrzebska, A. Olszyna, Z. Brzozka, Future applications of mxenes in biotechnology, nanomedicine, and sensors. Trends Biotechnol. 38(3), 264-279 (2020). https://doi. org/10.1016/j.tibtech.2019.09.001

71. M.A. Ali, L. Dong, J. Dhau, A. Khosla, A. Kaushik, Perspective-electrochemical sensors for soil quality assessment. J. Electrochem. Soc. 167(3), 037550 (2020). https:// doi.org/10.1149/1945-7111/ab69fe

72. M. Pirzada, Z. Altintas, Recent progress in optical sensors for biomedical diagnostics. Micromachines 11(4), 356 (2020). https://doi.org/10.3390/mi11040356
73. P.H. Lin, B.R. Li, Antifouling strategies in advanced electrochemical sensors and biosensors. Analyst 145(4), 1110 1120 (2020). https://doi.org/10.1039/C9AN02017A

74. H.S. Maghdid, K.Z. Ghafoor, A.S. Sadiq, K. Curran, K. Rabie, A novel ai-enabled framework to diagnose coronavirus covid 19 using smartphone embedded sensors: Design study. arXiv preprint arXiv:200307434. (2020)

75. M. Hackbart, X. Deng, S.C. Baker, Coronavirus endoribonuclease targets viral polyuridine sequences to evade activating host sensors. Proc. Natl. Acad. Sci. USA 117(14), 8094-8103 (2020). https://doi.org/10.1073/pnas.1921485117

76. H. Fischer, E. Tschachler, L. Eckhart, Pangolins lack IFIH1/MDA5, a cytoplasmic RNA sensor that initiates innate immune defense upon coronavirus infection. Front. Immunol. 11, 939 (2020). https://doi.org/10.3389/fimmu .2020 .00939

77. G. Nikaeen, S. Abbaszadeh, S. Yousefinejad, Application of nanomaterials in treatment, anti-infection and detection of coronaviruses. Nanomedicine 15(15), 1501-1512 (2020). https://doi.org/10.2217/nnm-2020-0117

78. C. Parolo, A.S. Greenwood, N.E. Ogden, D. Kang, C. Hawes et al., E-DNA scaffold sensors and the reagentless, singlestep, measurement of HIV-diagnostic antibodies in human serum. Microsyst. Nanoeng. 6(1), 1-8 (2020). https://doi. org/10.1038/s41378-019-0119-5

79. S. Kamal, M.I. Rosen, C. Lazar, L. Siqueiros, Y. Wang, E.S. Daar, H. Liu, Perceptions of people living with hiv and hiv healthcare providers on real-time measuring and monitoring of antiretroviral adherence using ingestible sensors: a qualitative study. AIDS Res. Treat. 2020, 1098109 (2020). https:// doi.org/10.1155/2020/1098109

80. H. Chen, G. He, Y. Chen, X. Zhang, Hepatitis B virus can be sensed by STING-dependent DNA sensors but suppresses the DNA sensing pathway in humans with acute and chronic hepatitis B virus infection. Res Square (2020). https://doi. org/10.21203/rs.2.23304/v1

81. M. Duhkinova, C. Crina, R. Weiss, V. Siciliano, Engineering intracellular protein sensors in mammalian cells. J. Vis. Exp. 158, e60878 (2020). https://doi.org/10.3791/60878

82. S. Dolai, M. Tabib-Azar, Microfabricated nano-gap tunneling current zika virus sensors with single virus detection capabilities. IEEE Sens. J. 20(15), 8597-8603 (2020). https://doi. org/10.1109/JSEN.2020.2984172

83. A.F. Versiani, E.M.N. Martins, L.M. Andrade, L. Cox, G.C. Pereira et al., Nanosensors based on LSPR are able to serologically differentiate dengue from zika infections. Sci. Rep. 10(1), 11302 (2020). https://doi.org/10.1038/s41598-02068357-9

84. S. Velanki, H.-F. Ji, Detection of feline coronavirus using microcantilever sensors. Meas. Sci. Technol. 17(11), 2964 (2006). https://doi.org/10.1088/0957-0233/17/11/015

85. S. Hassanpour, B. Baradaran, M. de la Guardia, A. Baghbanzadeh, J. Mosafer et al., Diagnosis of hepatitis via nanomaterial-based electrochemical, optical or piezoelectrical biosensors: a review on recent advancements. Mikrochim. 
Acta 185(12), 568 (2018). https://doi.org/10.1007/s0060 4-018-3088-8

86. W.-Y. Chang, P.-H. Sung, C.-H. Chu, C.-J. Shih, Y.-C. Lin, Phase detection of the two-port fpw sensor for biosensing. IEEE Sens. J. 8(5), 501-507 (2008). https://doi.org/10.1109/ JSEN.2008.918728

87. P. Teengam, W. Siangproh, A. Tuantranont, T. Vilaivan, O. Chailapakul, C.S. Henry, Multiplex paper-based colorimetric DNA sensor using pyrrolidinyl peptide nucleic acid-induced agnps aggregation for detecting MERS-CoV, MTB, and HPV oligonucleotides. Anal. Chem. 89(10), 5428-5435 (2017). https://doi.org/10.1021/acs.analchem.7b00255

88. L. Li, Y. Lu, C. Jiang, Y. Zhu, X. Yang et al., Actively targeted deep tissue imaging and photothermal-chemo therapy of breast cancer by antibody-functionalized drug-loaded x-ray-responsive bismuth sulfide@mesoporous silica coreshell nanoparticles. Adv. Funct. Mater. 28(5), 1704623 (2018). https://doi.org/10.1002/adfm.201704623

89. Y. Li, M. Hong, B. Qiu, Z. Lin, Y. Chen, Z. Cai, G. Chen, Highly sensitive fluorescent immunosensor for detection of influenza virus based on Ag autocatalysis. Biosens. Bioelectron. 54, 358-364 (2014). https://doi.org/10.1016/j. bios.2013.10.045

90. I.M. Khoris, K. Takemura, J. Lee, T. Hara, F. Abe, T. Suzuki, E.Y. Park, Enhanced colorimetric detection of norovirus using in situ growth of Ag shell on Au NPs. Biosens. Bioelectron. 126, 425-432 (2019). https://doi. org/10.1016/j.bios.2018.10.067

91. S.R. Ahmed, J. Kim, T. Suzuki, J. Lee, E.Y. Park, Enhanced catalytic activity of gold nanoparticle-carbon nanotube hybrids for influenza virus detection. Biosens. Bioelectron. 85, 503-508 (2016). https://doi.org/10.1016/j. bios.2016.05.050

92. R.K. Kankala, Y.H. Han, J. Na, C.H. Lee, Z. Sun et al., Nanoarchitectured structure and surface biofunctionality of mesoporous silica nanoparticles. Adv. Mater. 32(23), e1907035 (2020). https://doi.org/10.1002/adma.201907035

93. E. Doustkhah, J. Lin, S. Rostamnia, C. Len, R. Luque, X. Luo et al., Development of sulfonic-acid-functionalized mesoporous materials: synthesis and catalytic applications. Chemistry 25(7), 1614-1635 (2019). https://doi. org/10.1002/chem.201802183

94. J. Wang, Y. Xu, B. Ding, Z. Chang, X. Zhang, Y. Yamauchi, K.C. Wu, Confined self-assembly in two-dimensional interlayer space: monolayered mesoporous carbon nanosheets with in-plane orderly arranged mesopores and a highly graphitized framework. Angew. Chem. Int. Ed. 57(11), 2894-2898 (2018). https://doi.org/10.1002/anie.201712959

95. Z. Jia, Y. Ma, L. Yang, C. Guo, N. Zhou et al., $\mathrm{NiCo}_{2} \mathrm{O}_{4}$ spinel embedded with carbon nanotubes derived from bimetallic NiCo metal-organic framework for the ultrasensitive detection of human immune deficiency virus-1 gene. Biosens. Bioelectron. 133, 55-63 (2019). https://doi. org/10.1016/j.bios.2019.03.030

96. A. Rashidi, M. Omidi, M. Choolaei, M. Nazarzadeh, A. Yadegari et al., Electromechanical properties of vertically aligned carbon nanotube. Adv. Mater. Res. 705, 332336 (2013). https://doi.org/10.4028/www.scientific.net/ AMR.705.332

97. E. Proniewicz, A. Tąta, A. Szkudlarek, J. Świder, M. Molenda, M. Starowicz, Y. Ozaki, Electrochemically synthesized $\gamma-\mathrm{Fe}_{2} \mathrm{O}_{3}$ nanoparticles as peptide carriers and sensitive and reproducible sers biosensors Comparison of adsorption on $\gamma-\mathrm{Fe}_{2} \mathrm{O}_{3}$ versus Fe. Appl. Surf. Sci. 495, 143578 (2019). https://doi.org/10.1016/j.apsusc.2019.143578

98. J. Ding, W. Qin, Recent advances in potentiometric biosensors. TrAC Trend. Anal. Chem. 124, 115803 (2020). https:// doi.org/10.1016/j.trac.2019.115803

99. Q. Zhou, D. Tang, Recent advances in photoelectrochemical biosensors for analysis of mycotoxins in food. TrAC Trend. Anal. Chem. 124, 115814 (2020). https://doi.org/10.1016/j. trac.2020.115814

100. O. Hanpanich, K. Saito, N. Shimada, A. Maruyama, One-step isothermal RNA detection with LNA-modified MNAzymes chaperoned by cationic copolymer. Biosens. Bioelectron. 165, 112383 (2020). https://doi.org/10.1016/j.bios.2020.112383

101. M. Hasanzadeh, A.S. Nahar, S. Hassanpour, N. Shadjou, A. Mokhtarzadeh, J. Mohammadi, Proline dehydrogenaseentrapped mesoporous magnetic silica nanomaterial for electrochemical biosensing of L-proline in biological fluids. Enzyme Microb. Technol. 105, 64-76 (2017). https://doi. org/10.1016/j.enzmictec.2017.05.007

102. Y. Chen, C. Qian, C. Liu, H. Shen, Z. Wang et al., Nucleic acid amplification free biosensors for pathogen detection. Biosens. Bioelectron. 153, 112049 (2020). https://doi. org/10.1016/j.bios.2020.112049

103. F. Cui, H.S. Zhou, Diagnostic methods and potential portable biosensors for coronavirus disease 2019. Biosens. Bioelectron. 165, 112349 (2020). https://doi.org/10.1016/j. bios.2020.112349

104. G.C.H. Mo, C. Posner, E.A. Rodriguez, T. Sun, J. Zhang, A rationally enhanced red fluorescent protein expands the utility of fret biosensors. Nat. Commun. 11(1), 1848 (2020). https:// doi.org/10.1038/s41467-020-15687-x

105. S. Mavrikou, G. Moschopoulou, V. Tsekouras, S. Kintzios, Development of a portable, ultra-rapid and ultra-sensitive cell-based biosensor for the direct detection of the SARSCoV-2 s1 spike protein antigen. Sensors 20(11), 3121 (2020). https://doi.org/10.3390/s20113121

106. C. Bian, H. Wang, X. Zhang, S. Xiao, Z. Liu, X. Wang, Sensitive detection of low-concentration sulfide based on the synergistic effect of $\mathrm{rGO}, \mathrm{np}-\mathrm{Au}$, and recombinant microbial cell. Biosens. Bioelectron. 151, 111985 (2020). https://doi. org/10.1016/j.bios.2019.111985

107. V. Gaudin, Advances in biosensor development for the screening of antibiotic residues in food products of animal origin-a comprehensive review. Biosens. Bioelectron. 90, 363-377 (2017). https://doi.org/10.1016/j.bios.2016.12.005

108. M. Hasanzadeh, A. Karimzadeh, S. Sadeghi, A. Mokhtarzadeh, N. Shadjou, A. Jouyban, Graphene quantum dot as an electrically conductive material toward low potential detection: a new platform for interface science. J. Mater. 
Sci. Mater. Electron. 27(6), 6488-6495 (2016). https://doi. org/10.1007/s10854-016-4590-6

109. A. Dalal, H. Mohan, M. Prasad, C. Pundir, Detection methods for influenza a H1N1 virus with special reference to biosensors: a review. Biosci. Rep. 40(2), 3852 (2020). https://doi. org/10.1042/BSR20193852

110. B. Nohwal, R. Chaudhary, C. Pundir, Amperometric L-lysine determination biosensor amplified with L-lysine oxidase nanoparticles and graphene oxide nanoparticles. Process Biochem. 97, 57-63 (2020). https://doi.org/10.1016/j.procb io.2020.06.011

111. P. Kanagavalli, M. Veerapandian, Opto-electrochemical functionality of $\mathrm{Ru}$ (ii)-reinforced graphene oxide nanosheets for immunosensing of dengue virus non-structural 1 protein. Biosens. Bioelectron. 150, 111878 (2020). https://doi. org/10.1016/j.bios.2019.111878

112. R. Eivazzadeh-Keihan, P. Pashazadeh-Panahi, T. Mahmoudi, K.K. Chenab, B. Baradaran et al., Dengue virus: a review on advances in detection and trends-from conventional methods to novel biosensors. Microchim. Acta 186(6), 329 (2019). https://doi.org/10.1007/s00604-019-3420-y

113. A. Lopreside, Exploiting bioluminescence to enhance the analytical performance of whole-cell and cell-free biosensors for environmental and point-of-care applications. (2020)

114. S.Y. Kim, W. Jin, A. Sood, D.W. Montgomery, O.C. Grant et al., Characterization of heparin and severe acute respiratory syndrome-related coronavirus 2 (SARS-CoV-2) spike glycoprotein binding interactions. Antiviral Res. 181, 104873 (2020). https://doi.org/10.1016/j.antiviral.2020.104873

115. G. Pinto, P. Canepa, C. Canale, M. Canepa, O. Cavalleri, Morphological and mechanical characterization of DNA SAMs combining nanolithography with AFM and optical methods. Materials 13(13), 2888 (2020). https://doi. org/10.3390/ma13132888

116. P. Annamalai, M. Kanta, P. Ramu, B. Ravi, K. Veerapandian, R. Srinivasan, A simple colorimetric molecular detection of novel coronavirus (COVID-19), an essential diagnostic tool for pandemic screening. medRxiv (2020). https://doi. org/10.1101/2020.04.10.20060293

117. S. Zhang, X. Sun, W. Guo, J. Xu, Simultaneous detection of 2019 novel coronavirus and influenza virus by double fluorescent RT-PCR. Am J Lab Med. 5(1), 42-46 (2020). https ://doi.org/10.11648/j.ajlm.20200501.16

118. D. Zhang, X. Zhang, R. Ma, S. Deng, X. Wang et al., Ultrafast and onsite interrogation of severe acute respiratory syndrome coronavirus 2 (SARS-CoV-2) in environmental specimens via surface enhanced raman scattering (SERS). medRxiv (2020). https://doi.org/10.1101/2020.05.02.20086 876

119. C. Annalaura, F. Ileana, L. Dasheng, V. Marco, Making waves: coronavirus detection, presence and persistence in the water environment: state of the art and knowledge needs for public health. Water Res. (2020). https://doi.org/10.1016/j. watres.2020.115907

120. A. Kilianski, A.M. Mielech, X. Deng, S.C. Baker, Assessing activity and inhibition of middle east respiratory syndrome coronavirus papain-like and 3C-like proteases using luciferase-based biosensors. J. Virol. 87(21), 11955-11962 (2013). https://doi.org/10.1128/JVI.02105-13

121. L. Shi, Q. Sun, J. He, H. Xu, C. Liu et al., Development of SPR biosensor for simultaneous detection of multiplex respiratory viruses. Biomed. Mater. Eng. 26(s1), S2207-S2216 (2015). https://doi.org/10.3233/BME-151526

122. F.N. Ishikawa, H.-K. Chang, M. Curreli, H.-I. Liao, C.A. Olson et al., Electrical detection of the sars virus n-protein with nanowire biosensors utilizing antibody mimics as capture probes. ACS Nano 3(5), 1219-1224 (2009). https://doi. org/10.1021/nn900086c

123. T.J. Park, M.S. Hyun, H.J. Lee, S.Y. Lee, S. Ko, A self-assembled fusion protein-based surface plasmon resonance biosensor for rapid diagnosis of severe acute respiratory syndrome. Talanta 79(2), 295-301 (2009). https://doi.org/10.1016/j. talanta.2009.03.051

124. A. Mokhtarzadeh, R. Eivazzadeh-Keihan, P. Pashazadeh, M. Hejazi, N. Gharaatifar et al., Nanomaterial-based biosensors for detection of pathogenic virus. Trends Anal. Chem. 97, 445-457 (2017). https://doi.org/10.1016/j.trac.2017.10.005

125. C. Qi, J.-Z. Duan, Z.-H. Wang, Y.-Y. Chen, P.-H. Zhang et al., Investigation of interaction between two neutralizing monoclonal antibodies and SARS virus using biosensor based on imaging ellipsometry. Biomed. Microdevices 8(3), 247-253 (2006). https://doi.org/10.1007/s10544-006-8305-2

126. L. Huang, J. Chen, Z. Yu, D. Tang, Self-powered temperature sensor with seebeck effect transduction for photothermal-thermoelectric coupled immunoassay. Anal. Chem. 92(3), 28092814 (2020). https://doi.org/10.1021/acs.analchem.9b05218

127. S.A. Byrnes, T. Huynh, T.C. Chang, C.E. Anderson, J.J. McDermott et al., Wash-free, digital immunoassay in polydisperse droplets. Anal. Chem. 92(5), 3535-3543 (2020). https ://doi.org/10.1021/acs.analchem.9b02526

128. M. Hasanzadeh, H.N. Baghban, A. Mokhtarzadeh, N. Shadjou, S. Mahboob, An innovative immunosensor for detection of tumor suppressor protein p53 in unprocessed human plasma and cancer cell lysates. Int. J. Biol. Macromol. 105(Pt 1), 1337-1348 (2017). https://doi.org/10.1016/j.ijbio mac.2017.07.165

129. M. Hasanzadeh, S. Tagi, E. Solhi, A. Mokhtarzadeh, N. Shadjou, A. Eftekhari, S. Mahboob, An innovative immunosensor for ultrasensitive detection of breast cancer specific carbohydrate (ca15-3) in unprocessed human plasma and MCF-7 breast cancer cell lysates using gold nanospear electrochemically assembled onto thiolated graphene quantum dots. Int. J. Biol. Macromol. 114, 1008-1017 (2018). https:// doi.org/10.1016/j.ijbiomac.2018.03.183

130. M. Hasanzadeh, S. Tagi, E. Solhi, N. Shadjou, A. Jouyban, A. Mokhtarzadeh, Immunosensing of breast cancer prognostic marker in adenocarcinoma cell lysates and unprocessed human plasma samples using gold nanostructure coated on organic substrate. Int. J. Biol. Macromol. 118, 1082-1089 (2018). https://doi.org/10.1016/j.ijbiomac.2018.06.091

131. A. Padoan, C. Cosma, L. Sciacovelli, D. Faggian, M. Plebani, Analytical performances of a chemiluminescence 
immunoassay for SARS-CoV-2 IGM/IGG and antibody kinetics. Clin. Chem. Lab. Med. 58(7), 1081-1088 (2020). https://doi.org/10.1515/cclm-2020-0443

132. B. Meyer, G. Torriani, S. Yerly, L. Mazza, A. Calame et al., Validation of a commercially available SARS-CoV-2 serological immunoassay. Clin. Microbiol. Infect. 26, 1386-1394 (2020). https://doi.org/10.1016/j.cmi.2020.06.024

133. Z. Chen, Z. Zhang, X. Zhai, Y. Li, L. Lin et al., Rapid and sensitive detection of anti-SARS-CoV-2 IGG, using lanthanide-doped nanoparticles-based lateral flow immunoassay. Anal. Chem. 92(10), 7226-7231 (2020). https://doi. org/10.1021/acs.analchem.0c00784

134. E.R. Adams, R. Anand, M.I. Andersson, K. Auckland, J.K. Baillie et al., Evaluation of antibody testing for SARS-CoV-2 using ELISA and lateral flow immunoassays. medRxiv (Preprint, 2020). https://doi.org/10.1101/2020.04.15.20066407

135. T. Nicol, C. Lefeuvre, O. Serri, A. Pivert, F. Joubaud et al., Assessment of SARS-CoV-2 serological tests for the diagnosis of covid-19 through the evaluation of three immunoassays: two automated immunoassays (euroimmun and abbott) and one rapid lateral flow immunoassay (NG biotech). J. Clin. Virol. 129, 104511 (2020). https://doi.org/10.1016/j. jcv.2020.104511

136. D. Sevenler, A. Bardon, M. FernandezSuarez, L. Marshall, M. Toner, P.K. Drain, R.D. Sandlin, Immunoassay for HIV drug metabolites tenofovir and tenofovir diphosphate. ACS Infect. Dis. 6(7), 1635-1642 (2020). https://doi. org/10.1021/acsinfecdis.0c00010

137. R.M. Stalter, J.M. Baeten, D. Donnell, M.A. Spinelli, D.V. Glidden et al., Urine tenofovir levels measured by a novel immunoassay predict HIV protection. Clin. Infect. Dis. (2020). https://doi.org/10.1093/cid/ciaa785

138. W. Yang, D. Yang, S. Gong, X. Dong, L. Liu et al., An immunoassay cassette with a handheld reader for HIV urine testing in point-of-care diagnostics. Biomed. Microdevices 22(2), 39 (2020). https://doi.org/10.1007/s10544-020-00494-4

139. Z. Sharifi, M. Parsania, A. Pourfathollah, S. Haghighat, Prevalence of anti-HBc in HBsAg negative blood donors using two enzyme immunoassays kits. Sci. J. Iran Blood Transfus Organ 17(2), 83-90 (2020)

140. A. Eshetu, A. Hauser, D. Schmidt, B. Bartmeyer, V. Bremer et al., Comparison of two immunoassays for concurrent detection of $\mathrm{HCV}$ antigen and antibodies among HIV/HCV co-infected patients in dried serum/plasma spots. J. Virol. Methods 279, 113839 (2020). https://doi.org/10.1016/j.jviro met.2020.113839

141. J. Patel, P. Sharma, Design of a novel rapid immunoassay for simultaneous detection of hepatitis $C$ virus core antigen and antibodies. Arch. Virol. 165(3), 627-641 (2020). https://doi. org/10.1007/s00705-019-04518-0

142. A. Weiss, Concurrent engineering for lateral-flow diagnostics. IVD Technol. 5(7), 48-57 (1999)

143. K. Malik, H. Sadia, M.H. Basit, in Protein-based detection methods for genetically modified crops. ed. by (IntechOpen; 2018). https://doi.org/10.5772/intechopen. 75520
144. J. Hansson, H. Yasuga, T. Haraldsson, W. van der Wijngaart, Synthetic microfluidic paper: high surface area and high porosity polymer micropillar arrays. Lab Chip 16(2), 298-304 (2016). https://doi.org/10.1039/C5LC01318F

145. W. Guo, J. Hansson, W. van der Wijngaart, Viscosity independent paper microfluidic imbibition. The 20th International Conference on Miniaturized Systems for Chemistry and Life Sciences, MicroTAS 2016, 9-13 October 2016, Dublin, Ireland. 13-14 (2016)

146. L.A. Layqah, S. Eissa, An electrochemical immunosensor for the corona virus associated with the middle east respiratory syndrome using an array of gold nanoparticle-modified carbon electrodes. Microchim. Acta 186(4), 224 (2019). https ://doi.org/10.1007/s00604-019-3345-5

147. B. Zuo, S. Li, Z. Guo, J. Zhang, C. Chen, Piezoelectric immunosensor for sars-associated coronavirus in sputum. Anal. Chem. 76(13), 3536-3540 (2004). https://doi.org/10.1021/ ac035367b

148. C. Tuerk, L. Gold, Systematic evolution of ligands by exponential enrichment: rNA ligands to bacteriophage t4 DNA polymerase. Science 249(4968), 505-510 (1990). https://doi. org/10.1126/science.2200121

149. S.H. Rajabnejad, A. Mokhtarzadeh, K. Abnous, S.M. Taghdisi, M. Ramezani, B.M. Razavi, Targeted delivery of melittin to cancer cells by AS1411 anti-nucleolin aptamer. Drug Dev. Ind. Pharm. 44(6), 982-987 (2018). https://doi. org/10.1080/03639045.2018.1427760

150. J. Mosafer, A. Mokhtarzadeh, Cell surface nucleolin as a promising receptor for effective AS1411 aptamer-mediated targeted drug delivery into cancer cells. Curr. Drug Deliv. 15(9), 1323-1329 (2018). https://doi.org/10.2174/15672 01815666180724104451

151. S. Xie, Y. Du, Y. Zhang, Z. Wang, D. Zhang et al., Aptamerbased optical manipulation of protein subcellular localization in cells. Nat. Commun. 11(1), 1347 (2020). https://doi. org/10.1038/s41467-020-15113-2

152. M. Chen, Z. Tang, C. Ma, Y. Yan, A fluorometric aptamer based assay for prostate specific antigen based on enzymeassisted target recycling. Sens. Actuator B Chem. 302, 127178 (2020). https://doi.org/10.1016/j.snb.2019.127178

153. F. Tian, J. Zhou, R. Fu, Y. Cui, Q. Zhao, B. Jiao, Y. He, Multicolor colorimetric detection of ochratoxin a via structure-switching aptamer and enzyme-induced metallization of gold nanorods. Food Chem. 320, 126607 (2020). https://doi. org/10.1016/j.foodchem.2020.126607

154. S. Arshavsky-Graham, K. Urmann, R. Salama, N. MassadIvanir, J.G. Walter, T. Scheper, E. Segal, Aptamers vs. antibodies as capture probes in optical porous silicon biosensors. Analyst 145, 4991-5003 (2020). https://doi.org/10.1039/ D0AN00178C

155. M. Hasanzadeh, A. Zargami, H.N. Baghban, A. Mokhtarzadeh, N. Shadjou, S. Mahboob, Aptamer-based assay for monitoring genetic disorder phenylketonuria (PKU). Int. J. Biol. Macromol. 116, 735-743 (2018). https://doi.org/10.1016/j. ijbiomac.2018.05.028 
156. M. Hasanzadeh, N. Razmi, A. Mokhtarzadeh, N. Shadjou, $\mathrm{S}$. Mahboob, Aptamer based assay of plated-derived grow factor in unprocessed human plasma sample and MCF-7 breast cancer cell lysates using gold nanoparticle supported $\alpha$-cyclodextrin. Int. J. Biol. Macromol. 108, 69-80 (2018). https://doi.org/10.1016/j.ijbiomac.2017.11.149

157. M. Hasanzadeh, M. Moosavy, J. Soleymani, A. Mokhtarzadeh, Determination of aflatoxin M1 using aptamer based biosensior on the surface of dendritic fibrous nano-silica functionalized by amine groups. Anal. Methods 11(30), 3910-3919 (2019). https://doi.org/10.1039/C9AY01185D

158. S. Wadhwa, A.T. John, S. Nagabooshanam, A. Mathur, J. Narang, Graphene quantum dot-gold hybrid nanoparticles integrated aptasensor for ultra-sensitive detection of vitamin D3 towards point-of-care application. Appl. Surf. Sci. (2020). https://doi.org/10.1016/j.apsusc.2020.146427

159. R. Eivazzadeh-Keihan, P. Pashazadeh-Panahi, B. Baradaran, A. Maleki, M. Hejazi, A. Mokhtarzadeh, M. de la Guardia, Recent advances on nanomaterial based electrochemical and optical aptasensors for detection of cancer biomarkers. TrAC Trend Anal. Chem. 100, 103-115 (2018). https://doi. org/10.1016/j.trac.2017.12.019

160. H. Safarpour, S. Dehghani, R. Nosrati, N. Zebardast, M. Alibolandi, A. Mokhtarzadeh, M. Ramezani, Optical and electrochemical-based nano-aptasensing approaches for the detection of circulating tumor cells (CTCs). Biosens. Bioelectron. 148, 111833 (2020). https://doi.org/10.1016/j. bios.2019.111833

161. M. Yousefi, S. Dehghani, R. Nosrati, H. Zare, M. Evazalipour et al., Aptasensors as a new sensing technology developed for the detection of MUC1 mucin: a review. Biosens. Bioelectron. 130, 1-19 (2019). https://doi.org/10.1016/j. bios.2019.01.015

162. L. Wang, X. Peng, H. Fu, C. Huang, Y. Li, Z. Liu, Recent advances in the development of electrochemical aptasensors for detection of heavy metals in food. Biosens. Bioelectron. 147, 111777 (2020). https://doi.org/10.1016/j. bios.2019.111777

163. C. Zhu, L. Li, G. Yang, S. Fang, M. Liu et al., Online reaction based single-step capillary electrophoresis-systematic evolution of ligands by exponential enrichment for ssDNA aptamers selection. Anal. Chim. Acta 1070, 112-122 (2019). https://doi.org/10.1016/j.aca.2019.04.034

164. L. Gold, Selex: how it happened and where it will go. J. Mol. Evol. 81(5-6), 140-143 (2015). https://doi.org/10.1007/ s00239-015-9705-9
165. A. Mokhtarzadeh, M. Tabarzad, J. Ranjbari, M. de la Guardia, M. Hejazi, M. Ramezani, Aptamers as smart ligands for nano-carriers targeting. TrAC Trends Anal. Chem. 82, 316-327 (2016). https://doi.org/10.1016/j.trac.2016.06.018

166. W. Yi-Xian, Y. Zun-Zhong, S. Cheng-Yan, Y. Yi-Bin, Application of aptamer based biosensors for detection of pathogenic microorganisms. Chin. J. Anal. Chem. 40(4), 634-642 (2012). https://doi.org/10.1016/S1872-2040(11)60542-2

167. D.G. Ahn, I.J. Jeon, J.D. Kim, M.S. Song, S.R. Han et al., RNA aptamer-based sensitive detection of SARS coronavirus nucleocapsid protein. Analyst 134(9), 1896-1901 (2009). https://doi.org/10.1039/b906788d

168. S.-J. Cho, H.-M. Woo, K.-S. Kim, J.-W. Oh, Y.-J. Jeong, Novel system for detecting SARS coronavirus nucleocapsid protein using an ssDNA aptamer. J. Biol. Bioeng. 112(6), 535-540 (2011). https://doi.org/10.1016/j.jbiosc.2011.08.014

169. M. Afsharzadeh, M. Hashemi, A. Mokhtarzadeh, K. Abnous, M. Ramezani, Recent advances in co-delivery systems based on polymeric nanoparticle for cancer treatment. Artif. Cells Nanomed. Biotechnol. 46(6), 1095-1110 (2018). https://doi. org/10.1080/21691401.2017.1376675

170. C. Roh, S.K. Jo, Quantitative and sensitive detection of SARS coronavirus nucleocapsid protein using quantum dots-conjugated RNA aptamer on chip. J. Chem. Technol. Biotechnol. 86(12), 1475-1479 (2011). https://doi.org/10.1002/jctb.2721

171. I. Sola, F. Almazan, S. Zuniga, L. Enjuanes, Continuous and discontinuous RNA synthesis in coronaviruses. Annu. Rev. Virol. 2(1), 265-288 (2015). https://doi.org/10.1146/annur ev-virology-100114-055218

172. C.M. Niemeyer, M. Adler, R. Wacker, Detecting antigens by quantitative immuno-PCR. Nat. Protoc. 2(8), 1918-1930 (2007). https://doi.org/10.1038/nprot.2007.267

173. News in brief, First NGS-based COVID-19 diagnostic. Nat. Biotechnol. 38(7), 777 (2020). https://doi.org/10.1038/s4158 7-020-0608-y

174. E.B. Bahadır, M.K. Sezgintürk, Applications of commercial biosensors in clinical, food, environmental, and biothreat/ biowarfare analyses. Anal. Biochem. 478, 107-120 (2015). https://doi.org/10.1016/j.ab.2015.03.011

175. Y.S. Malik, A.K. Verma, N. Kumar, N. Touil, K. Karthik et al., Advances in diagnostic approaches for viral etiologies of diarrhea: From the lab to the field. Front. Microbiol. 10, 1957 (2019). https://doi.org/10.3389/fmicb.2019.01957 